Project Report

\title{
SOFC Stack and System Modeling, Fault Diagnosis and Control
}

Khaliq Ahmed ${ }^{1}$, Periasamy Vijay ${ }^{1}$, Moses Tadé ${ }^{1,}{ }^{*}$, Amirpiran Amiri ${ }^{2}$, Zongping Shao ${ }^{1}$, Karl Föger ${ }^{3}$

1. Chemical Engineering Department, Curtin University, Kent St, Perth, WA 6102, Australia; E-Mails: khaliq.ahmed83@alumni.ic.ac.uk; V.Periasamy@curtin.edu.au; M.O.Tade@curtin.edu.au; Zongping.shao@curtin.edu.au

2. Energy and Bioproducts Research Institute, School of Engineering \& Applied Science, Aston University, Birmingham B4 7ET, United Kingdom; E-Mail: a.p.amiri@aston.ac.uk

3. Xinnotec Pty Ltd. Kew, Victoria 3101, Australia; E-Mail: kf@xinnotec.com.au

* Correspondence: Moses Tadé; E-Mail: M.O.Tade@curtin.edu.au

Academic Editor: Ramon Costa-Castello

Special Issue: Modeling and Control of Fuel Cell Systems

Journal of Energy and Power Technology

2021, volume3,issue 1

doi:10.21926/jept.2101004
Received: July 31, 2020

Accepted: December 15, 2020

Published: January 18, 2021

\begin{abstract}
This report is an account of research and development activities undertaken by the Centre for Process Systems Computations, Department of Chemical Engineering at Curtin University, Western Australia in the area of solid oxide fuel cells. The focus of work of the group included 1)effect of cell macrostructure and microstructure on electrochemical performance with a view to optimise both macro- and micro-structure 2) electrochemistry modeling for simulating electrochemical performance 3) internal reforming aspects impacting performance at cell/stack and system levels 4) system level modeling investigating cell internal profiles (temperature, gas composition), homogeneity improvement, thermal management, anode recycle, fuel diversity, oxygen quality, and 5) monitoring for diagnostics, optimisation and control. The report summarizes work done over a period of 15 years and highlights areas of research gaps and future directions for research in the path to mass-scale commercialisation of the solid oxide fuel cell technology.
\end{abstract}

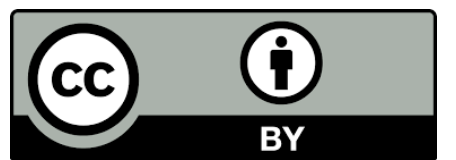

(C)2021 by the author. This is an open access article distributed under the conditions of the Creative Commons by Attribution License, which permits unrestricted use, distribution, and reproduction in any mediumor format, provided the original work is correctly cited. 


\section{Keywords}

SOFC stack; process synthesis and analysis; optimisation; simulation studies; control; process diagnostics; electrochemistry; thermal management

\section{Introduction}

Population growth and human activities - in particular, increased digitalization, transport electrification, consumption behaviour and rapid growth in the building (residential and commercial) sector are driving an increasing need for electricity. In this regard, fuel cells are attractive as they are highly efficient, practically noiseless and produce substantially lower emissions than conventional power plants. Amongst the different types of fuel cells, the solid oxide fuel cell (SOFC) technology, despite its challenges relating to durability and manufacturing cost, continues to draw attraction and attention by researchers and developers of commercial products for power generation. The most compelling reason for this, is the fact that the SOFC can contribute to a significant reduction in global emissions even when operating on a fossil fuel like the abundantly available reticulated pipeline natural gas, on account of the high efficiency of conversion of the chemical energy in the fuel to electrical energy and its ability to modulate power without significant efficiency loss. Net electrical efficiencies of 50-60\% have been reported, even for small generators $[1,2]$, which is significantly higher than any of the conventional technologies, particularly for smallscale distributed power generation; the SOFC is a highly efficient and fully controllable power source. Thus, SOFC is the ideal technology to ensure a stable grid when combined with intermittent renewable sources, as well as enable the transition from fossil-fuel dependency to a sustainable world utilizing renewable energy sources for electricity generation. SOFC technology not only provides a solution in the transition period, it can be a part of the renewable solution as it is amenable to operating on renewable fuels like bio-ethanol, landfill gas and bio-gas and green hydrogen [3-8].

Research and development in the SOFC field are currently focussed mainly in three areas - I) manufacturability (volume production and cost reduction) ii) reliability (reduced maintenance cycle and component failure i.e. reduced downtime) and iii) life (reduced material degradation and degradation of performance). Modeling is an important tool in each of these areas. At the cell/electrode level, modeling can provide valuable insight into the physics and chemistry of the internal processes occurring within the cell. Such insight can lead to designing components with improved performance and reduced degradation. Flow field and thermal and structural stability of the stack can be designed and improved by modeling without the need for expensive and timeconsuming experiments. System level modeling enables simulation for performance prediction and the development of diagnostic tools as well as the formulation of control algorithms, both for steady state and dynamic operating conditions.

In this technical report we bring together the work carried out by our research team including collaborative work with our previous industrial partner Ceramic Fuel Cells Ltd., some of which were funded by the Australian Research Council. The focus of the work of our group has been in the area of modeling and control - at the cell, stack and system levels, both steady state and dynamic. 


\section{Modeling of SOFC}

\subsection{Cell and Stack Level Modeling}

In our early work [9] a 3D CFD model of an internal reforming cell was developed where the anode was treated as two distinct layers - a diffusion layer and a catalyst layer. As shown in Figure 1 , the model was validated with experimental data in the range of $700-750^{\circ} \mathrm{C}$ from a single layer stack with cells and interconnects of the same geometry. The complex interaction between macroand micro-structural parameters of the anode was found to significantly influence the distribution of the key parameters - temperature, reaction rates and species concentration profiles along different spatial domains. An optimal set of the anode diffusion layer ( $A D L$ ) microstructure, which promotes the reforming reaction rate, did not necessarily result in improved SOFC performance. For example, for the chosen reaction kinetics scheme [10], a porosity of 0.4 was found to be optimal for the internal reforming reaction in terms of methane conversion and temperature drop caused by the endothermic steam reforming reaction. However, a porosity of 0.2 was found to be more effective from the consideration of heat released by the exothermic electrochemical reactions. Different kinetic models will lead to different concentration and temperature profiles, which, in turn, will result in differences in the rates of physical processes within the pores of the anode and in the external supply and distribution channels in the anode chamber.

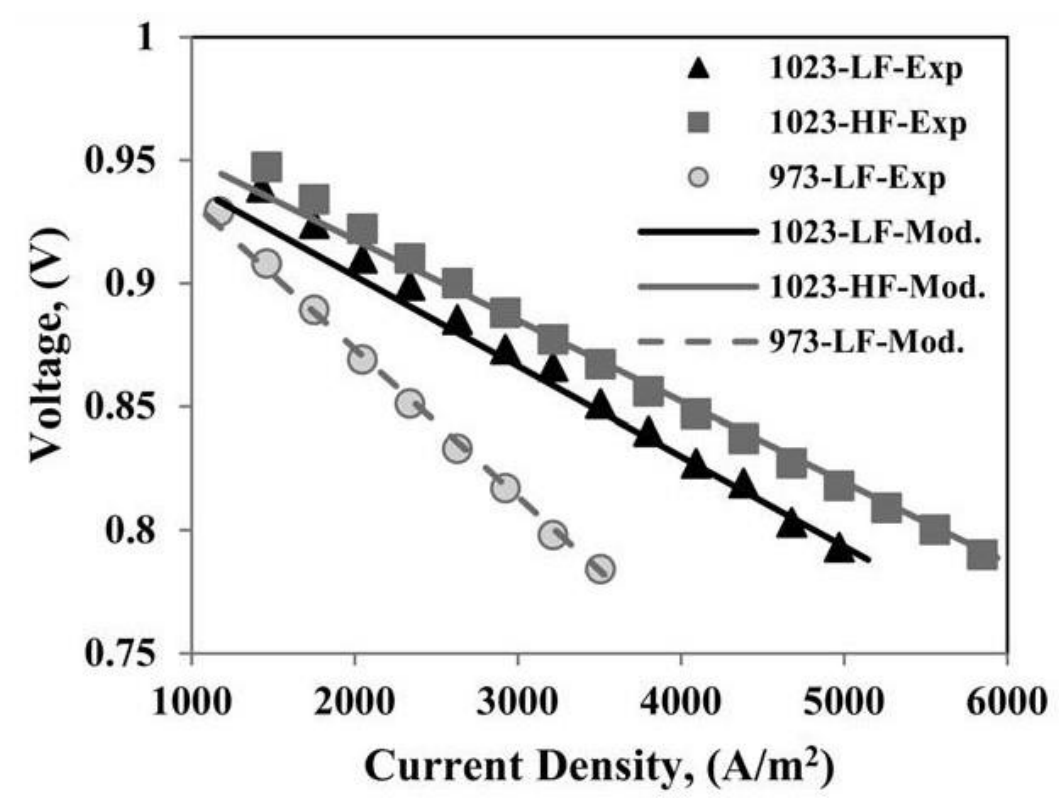

Figure 1 Validation of 3D CFD model with experimental data of the same geometry. LF: $0.067 S L M$ (dry gas) + 0.073SLM (steam); HF: 0.127SLM (dry gas) + 0.139SLM (steam) [3].

A study of the effects of pore size [9] showed that pore size affects reaction rates, and consequently, species molar fractions and electrochemical performance, in addition to temperature profiles. While larger pore sizes reduce diffusion resistance (as evidenced by smaller differences of the species concentrations between gas-phase and the ADL), smaller pores result in higher reaction rates. An optimal pore-size is therefore found in the mid-range.

An increase in the macrostructural parameter of ADL thickness affects the SOFC performance predominantly within the initial length of the cell; hydrogen residence time was increased and the 
reforming reaction rate was reduced due to dilution of the reactants with hydrogen. The developed model is a powerful tool for studying the complex interactions of the chemical reactions involved and the accompanying physical processes.

\subsubsection{Tank in Series SOFC Modeling}

SOFC modeling at the cell and stack levels are useful for analysis of design considerations for flow fields and manifolds. CFD models are very effective, but with the disadvantage of high computational costs. In our work [11] the lumped parameter modeling concept of tank in series reactor (TSR) commonly used for modeling chemical reactors was introduced for SOFC cell level modeling to capture the spatial variation in the variables. The developed model for planar SOFC accounted for the charge balances in the electrodes and electrolyte and the component and energy balances in the cell and simulates the potentiostatic operation of the cell.

A two-dimensional model of the cell area was constructed through this modeling approach with lumping in the direction perpendicular to the direction of flow. Mass and energy balance equations were formulated for each lump along with the constitutive relations governing the electrochemical phenomena. The model generated polarisation curves were then validated using literature data [12]. The model was utilised to study the effect of the flow configurations on the spatial distributions of the variables. Three flow configurations were studied, namely, co-flow, counter-flow and cross-flow configurations. The transient behaviour of the key variables like current density, temperature and concentrations were also studied. The study found that the co flow configuration is most suited for SOFC as it provided uniform transient behaviour throughout the cell along with a good efficiency. We applied the same TSR methodology to analyse the spatial distributions in a tubular SOFC in [13]. One of the model simulation results for the temperature distribution along the tube is shown in Figure 2. The results show significant gradients within the tubular cell with a maximum difference between the inlet and in-cell temperature of $500 \mathrm{~K}$, which is comparable to trends reported in the literature $[14,15]$. This demonstrates the ability of the TSR methodology to simulate SOFCs with tubular configurations.
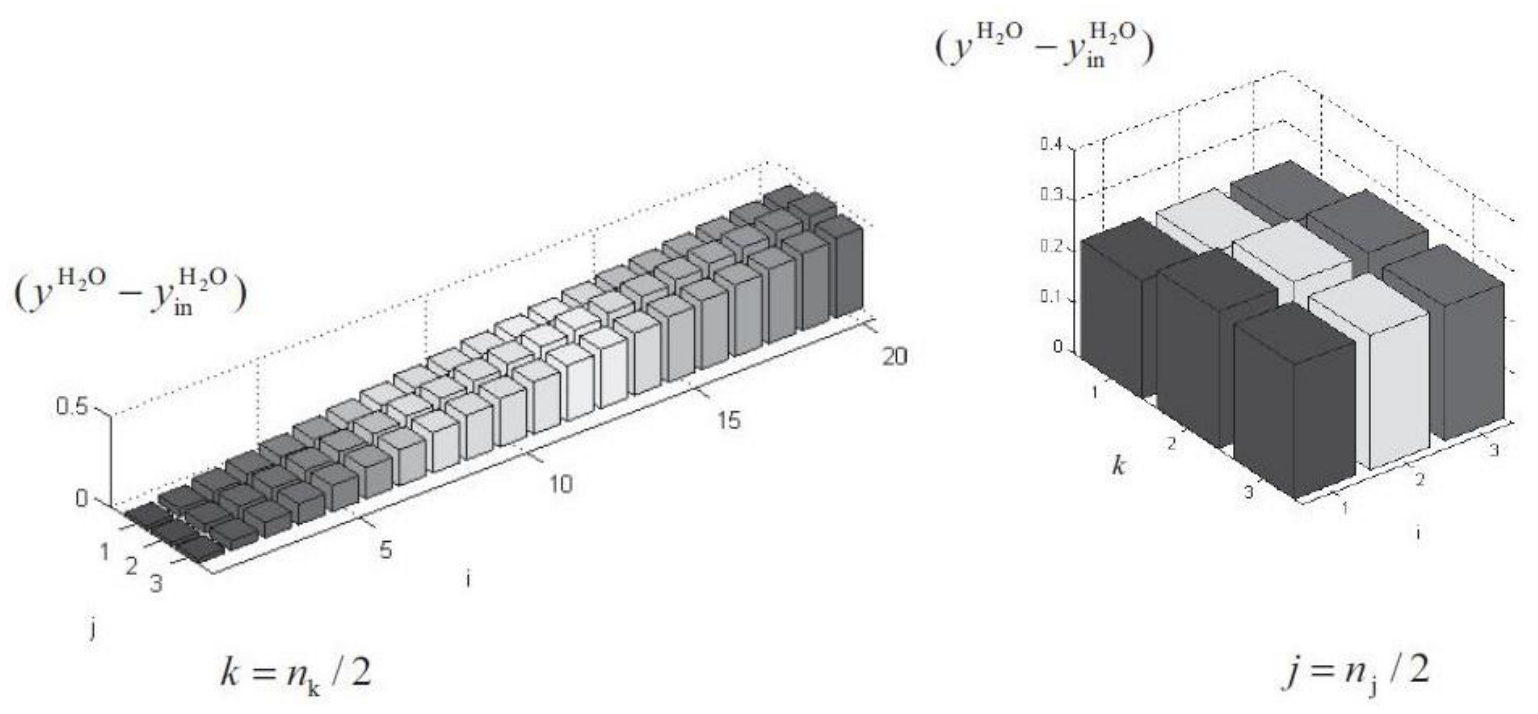

Figure 2 Local current density predicted by TSR model for the tubular SOFC stack. $i_{\text {avg }}^{A}=$ $1360 \mathrm{~A} / \mathrm{m}^{2} ; T_{\text {avg }}^{C}=1266 \mathrm{~K} ; \mathrm{T}_{\text {avg }}^{A}=1283 \mathrm{~K} ; \mathrm{T}_{\text {avg }}^{S}=1283 \mathrm{~K}[13]$. 


\subsubsection{Planar SOFC Thermal Management}

Excessive thermal gradients inside the cell during operation can result in many kinds of failures by inducing thermal stresses. It is well documented that air flow can be used to reduce the thermal gradients in planar SOFC $[16,17]$. However, this involves the trade-offs of reduced cell average temperature and reduced fuel utilisation, which are not desirable. A novel design for the planar SOFC interconnect was proposed by us in [18] to reduce the excessive thermal gradients. This design tackles the problem by introducing a secondary air stream in the counter direction and orifice based localised cooling to even out temperature differences and reduce hot spots. This way the thermal distribution can be evened out without drastic change in overall air inlet flow. Furthermore, the presence of orifices allows mass transfer between the two air streams and thus aids localised cooling. A schematic of the proposed design is shown in Figure 3. The proposed design involved minor changes to the interconnect and the inlet manifold design, which can be fabricated using standard methods while retaining all the advantages of the planar cell configuration. The effectiveness of this design was evaluated through model simulations.A TSR model of thehydrogen fuelled planar SOFC including the secondary air stream is developed and is utilised to compare the performance of the normal and the new designs in terms of the temperature uniformity in the cell. Using simulations, the primary air channel inlet flow rate and the secondary air channel inlet temperature are identified as suitable variables for manipulation so as to achieve the goal of temperature uniformity, while maintaining a desirable fuel utilisation (FU) and cell operating temperature. It is concluded from the simulations that the new design can restrict the temperature difference across the cell to less than $2 \mathrm{~K}$ over the range of operating voltages while achieving a FU of above 75\% [18-20].
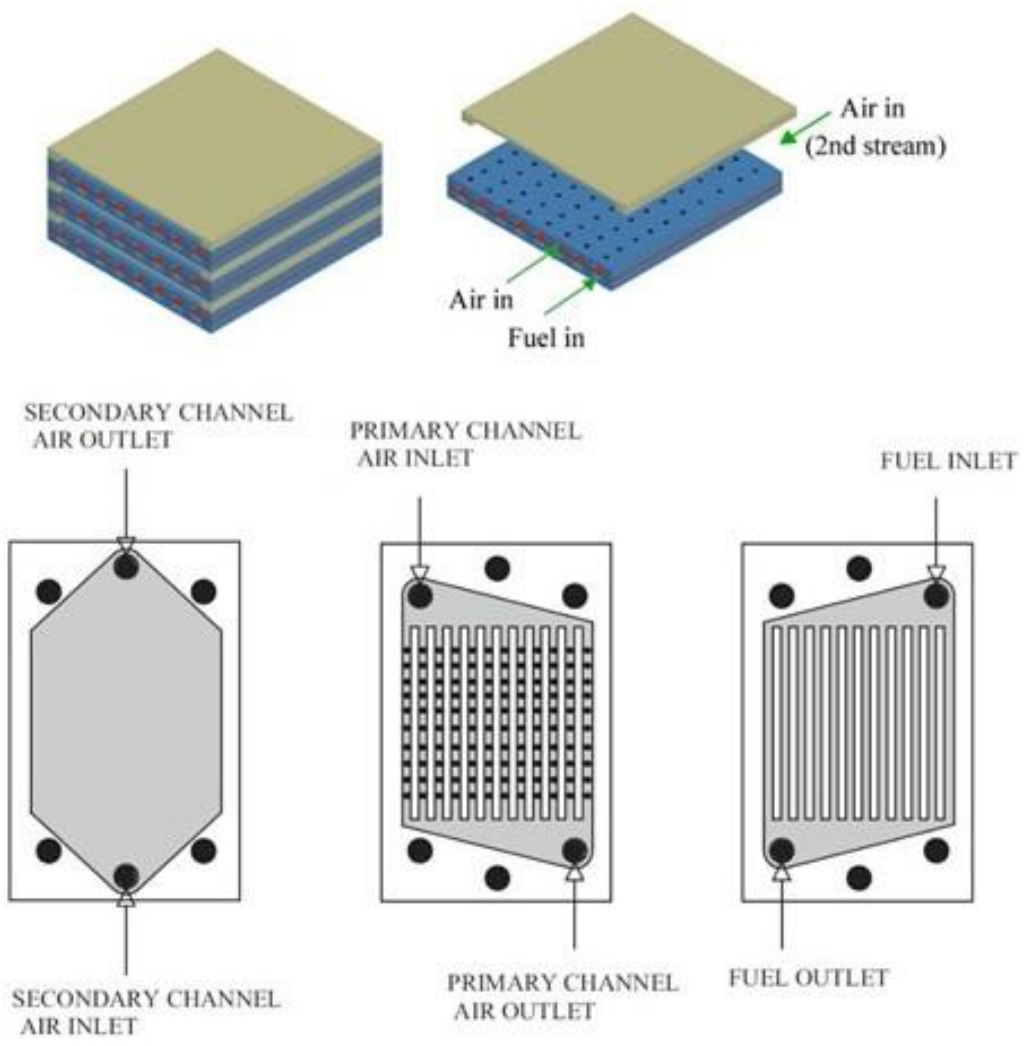

Figure 3 Schematic of the proposed interconnect and manifold designs for thermal management [19]. 
Understanding the thermal behaviour of the SOFC is essential for formulating good thermal management plans. Effective thermal management leads to minimising thermal gradients and hot spots in the cell during various operating modes resulting in improved durability of the cell. For the purpose of gaining an enhanced understanding of SOFC thermal behaviour, we conducted studies of the SOFC in a heated furnace environment [20]. The TSR modeling method is scaled for cell level modeling in creating a quasi-3D model with 4 layers accounting for various modes of heat transfer such as conduction, convection and radiation. The heat transfer characteristics of the cell in a heated environment were studied under adiabatic and non-adiabatic conditions. The experimental set-up for model validation contains the SOFC within a temperature-controlled furnace. Three models were formulated for understanding the cell thermal behaviour. A simple model that represents a perfectly insulated cell, an improved model that also accounts for the convective and conductive heat transfers between cell layers but is still insulated from atmosphere and a comprehensive model that includes the radiation heat transfer to the surrounding environment in addition to the internal heat transfer mechanisms.

Continuing with this development of the TSR model, a short stack consisting of three cells was modelled with the same approach for the purpose of evaluating the thermal behaviour and devising thermal management strategies [21]. Three different strategies for improving thermal behaviour of the stack were studied, viz. using excess air, adjustment of gas inlet temperature difference and usage of air enriched with oxygen. It was found that that temperature gradient minimisation can be achieved only at the cost of efficiency. All the three strategies investigated result in reduced energy conversion efficiency, therefore requiring trade-off optimisation. To reveal the trade-offs for design purposes, a multi-objective optimisation was performed with the two objectives of reducing thermal gradients in the stack and increasing stack efficiency. The trade-off optimisation is presented in the form of Pareto chart in Figure 4. This will serve to guide the design decision process using acceptable thresholds for the thermal gradients and efficiency. If the thermal gradient minimisation is dominant for a particular application, then a region near point III can be chosen at the cost of efficiency. If obtaining high efficiency is the primary objective then strategies can be devised to achieve operation near point I.

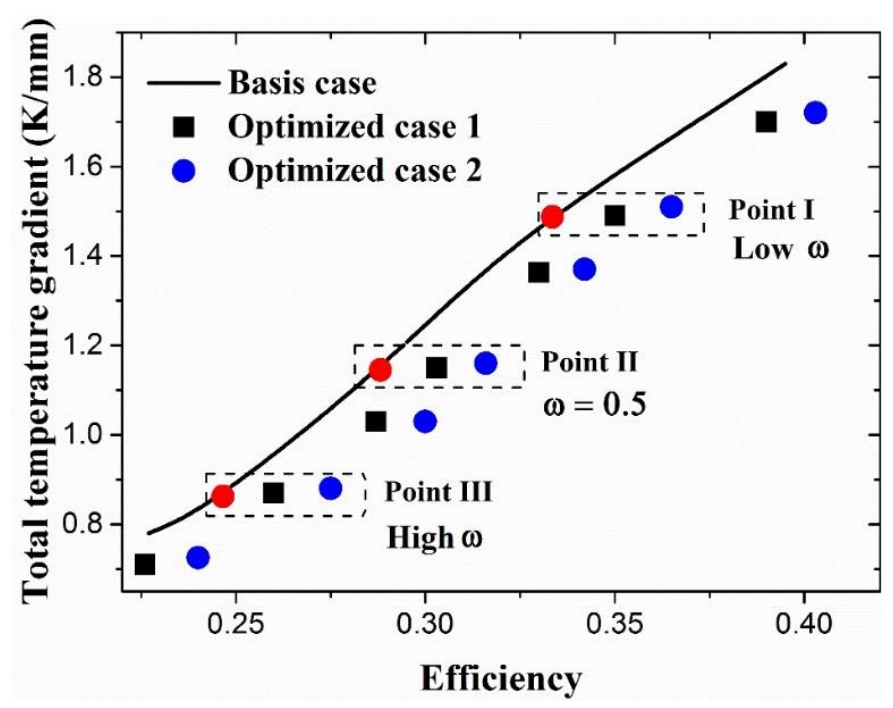

Figure 4 Trade-off between efficiency and temperature gradient; Pareto points for basis case and optimization trials $\left(F_{\mathrm{H}_{2}}=900 \mathrm{ml} / \mathrm{min}\right)$ [21]. 
The methane reforming reaction is a key element of SOFCs operating on methane-based fuels such as natural gas, biogas, pre-reformed higher hydrocarbons (eg. propane or butane). Both, the extent of reforming and the rate at which it occurs directly contribute to the fuel cell performance. Furthermore, the extent of reforming indirectly contributes to fuel cell efficiency owing to heat abstraction by the endothermic steam reforming reaction which increases fuel value and impacts on the cooling requirements by external air. The rate of reforming i.e. the kinetics of the steam reforming reactions plays a significant role in the profiles of voltage, gas composition, temperature and current density along the cell and stack - all of which contribute to cell and stack degradation and/or thermal stresses. In general, the reactions considered to be involved are the methane steam reforming reaction, MSR (1) and the water-gas shift reaction, WGS (2):

$$
\begin{gathered}
\mathrm{CH}_{4}+\mathrm{H}_{2} \mathrm{O} \rightleftharpoons \mathrm{CO}+3 \mathrm{H}_{2} \\
\mathrm{CO}+\mathrm{H}_{2} \mathrm{O} \rightleftharpoons \mathrm{CO}_{2}+\mathrm{H}_{2}
\end{gathered}
$$

There are two approaches to modeling the reforming reactions $-i)$ assuming the reactions are at thermodynamic equilibrium and ii) using kinetic expressions derived from out-of-cell or in-cell experiments. More commonly reaction (2) is assumed to be at equilibrium and reaction (1) is considered to be kinetically controlled. In a comprehensive analysis [22] our work in this area showed how different modeling schemes - thermodynamic, kinetic and combinations of kinetic and thermodynamic schemes result in vastly different distribution of temperature, current, voltage and compositions on the SOFC anode. The results also showed that a third reaction - the reverse methanation reaction, RMTN (3), when considered to be occurring directly on the anode surface leads to significant differences in the profiles.

$$
\mathrm{CH}_{4}+2 \mathrm{H}_{2} \mathrm{O} \rightleftharpoons \mathrm{CO}_{2}+4 \mathrm{H}_{2}
$$

From their study of intrinsic steam reforming, Xu and Froment [23] concluded that it is unlikely that $\mathrm{CO}_{2}$ would be formed solely out of $\mathrm{CO}$ and therefore the reaction scheme needs to account for the direct parallel formation of $\mathrm{CO}_{2}$ via reaction (3).

Different modeling schemes led to significant differences in some of the performance parameters like maximum current density, cell temperature gradient, average cell voltage and cell efficiency. There are significant differences for different kinetic expressions, see Ahmed \& Föger [10] and Achenbach\& Riensche [24]. Furthermore, there are significant differences when the reverse methanation reaction is included in the model and when the WGS reaction is kinetically controlled (Tingey [25]).

Steepest profiles of current density, $\mathrm{H}_{2}$ mole fraction and Nernst voltage are obtained with a thermodynamic model for both MSR and WGS and the inclusion of RMTN makes little or no difference. The latter is because under equilibrium conditions RMTN is a combination of the MSR and WGS reactions. The flattest profiles are obtained with a kinetic model for MSR combined with a kinetic or thermodynamic model for WGS, while not including RMTN. The fact that there is little difference between models with kinetic expressions for WGS and those assuming thermodynamic equilibrium indicates that the WGS reaction is at or near equilibrium under SOFC operating conditions, where the reaction progress is shifted to the right due to consumption of $\mathrm{H}_{2}$ by the fuel cell reaction i.e. the hydrogen electrochemical oxidation. This work highlighted the importance of 
developing internal reforming models which are representative of anodes in real systems with particular attention to MSR kinetics and the inclusion of RMTN. It was shown that both of these can significantly influence the profiles of gas composition, temperature, current density and voltage. Furthermore, the associated mass and heat transport limitations can also influence these profiles. These are important considerations when developing simulation models and control algorithms for the entire system including the balance of plant (BoP).

A HYSYS (Aspen) model for an ethane fed internal reforming SOFC was developed using in-built unit operation modules of HYSYS and without the need for linking with any programming code [26]. The model includes electrochemistry and diffusion and reforming kinetics. Three methods for representing the SOFC were investigated, out of which the recycled reforming model gave reasonable results over a wide range of operating conditions. The electrochemical model that gives good agreement with experimental data was also identified. From the simulations, it was concluded that the developed model is reasonably accurate over a wide operating range and can be used for steady state analysis. Two main drawbacks of this work are the assumptions of isothermal conditions for internal reforming and the use of a GIBBS reactor for the fuel cell reactions. In a real system the SOFC stack does not operate in an isothermal mode. Our subsequent work [27] addresses these issues by using a non-isothermal plug-flow reactor for the internal reforming MSR, an equilibrium reactor for WGS and a conversion reactor for the fuel cell oxidation reactions to represent the fuel utilisation level. The main findings from this work are presented in the following section as this was a system level study compared to [26], which was a cell-level study.

\subsection{Modeling and Simulation at the System Scale}

In the area of multi-scale modeling of SOFC systems, the application of suitable commercial flowsheet software was adopted for a number of reasons. Firstly, it obviates the need for writing codes for modeling of process units like heat-exchangers, chemical reactors and burners or process operations like fluid flow and separation. Most commercial process simulators include model libraries for the various units and operations in process and chemical engineering and these are available as in-built modules. The SOFC system units (except detailed electrochemical reactors including fuel cells) can be selected and used from these established high-fidelity libraries. Detailed modeling and simulation of the SOFC is possible through the interfacing of these process simulators with modeling environments such as Aspen Custom Modeler (ACM), numerical routines written in an external platform like FORTRAN, C+ or in embedded Spreadsheets as in ASPEN HYSYS and Pro-II. The externally coded module will be integrated to the main flowsheet by using efficient tools such as ACM, CAPE-OPEN, and integrated Spreadsheet. Secondly, the estimation of the thermo-physical properties of chemical species/mixtures, reaction kinetics, and equilibrium, etc., that are involved in SOFC system operation can be conducted using well established databases and thermodynamicsbased property methods available in the commercial simulators. Thirdly, they offer efficient process analysis facilities such as sensitivity analysis, optimisation, and specification design, etc., that are essential tools for SOFC process synthesis and analysis.

Using this approach, a simulation platform was developed [28] in Aspen. This multiscale simulation included models at the element (OD), channel (1D) and cell (2D) scales. A SOFC model was initially developed in ACM to be deployed as an imported model in Aspen Plus. In order to demonstrate the capabilities and the preciseness of the model prediction at various scales, several 
case studies were conducted including dynamic and steady-state performances modeling, sensitivity analysis and optimisation strategies. The model allows for modification of the governing equations which is a vital feature for internal and external reformation processes and also fuel quality or fuel type variation. Moreover, simulation of the fuel and air flow patterns, including coflow, counter-flow, and cross-flow patterns, were applied at the flowsheet level. The model has been used for studies at various scales. Initially, the dynamic behaviour of microscale element of a cell was examined by using the platform capabilities for lumped modeling. Even though a dynamic and distributed model is promising for SOFC system dynamics evaluation, OD dynamic models are still widely reported in the literature. Our study [28] demonstrated the effectiveness of such a model for investigation of the SOFC dynamics. This element was later used as the building block for more complex SOFC configurations. Secondly, at the channel (1D) scale, a sensitivity analysis was performed to evaluate the effects of different flow patterns in air and fuel sides. Thirdly, the effect of fuel and air flow rates on the cell internal profiles was tested on a 2D assembly. Finally, internal thermal gradients study was conducted by using 2D model. This led to an optimal air distribution profile which minimises the internal temperature gradients (Figure 5) and avoids hot spots in the cell. The most important outcome was the established numerical platform, in Aspen Plus, that could be readily employed for a wide spectrum of SOFC system technical challenges without further programming tasks. Accordingly, several further publications were presented based on this platform, each, dealing with a state-of-the-art challenge relevant to SOFC Research and Development. A brief summary of these is presented below.

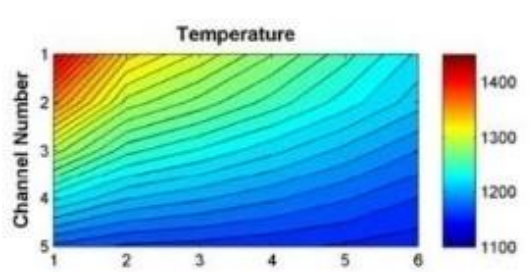

Current Density, A/m²
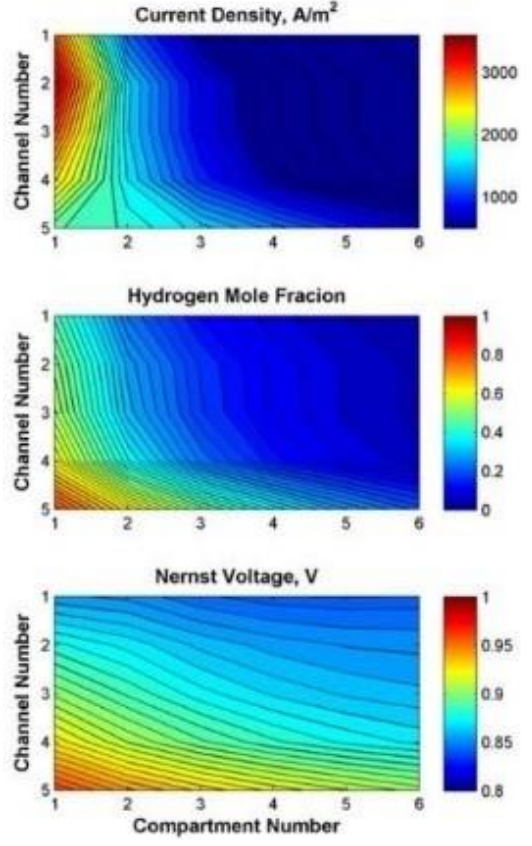

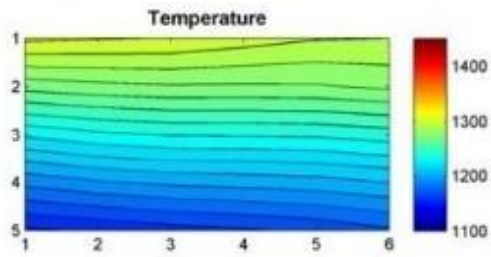

Current Density, A/m²
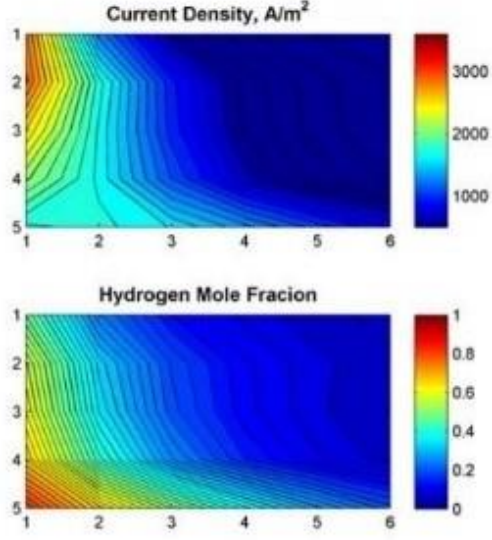

Nernst Voltage, $\mathrm{v}$

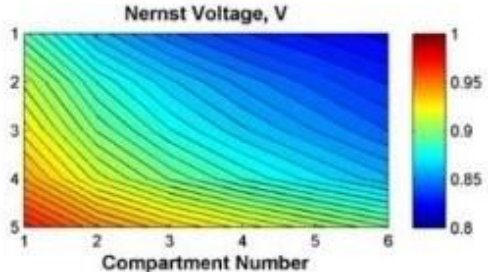

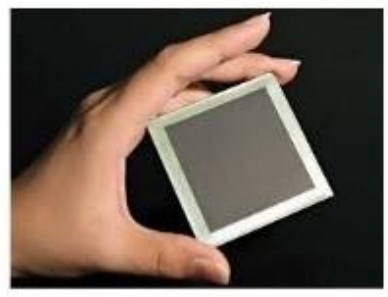

Figure 5 2D visualisation of internal variables at cell scale using flowsheet data, (left) basis case, (right) optimised case [28]. 
The impact of the BoP units on the SOFC thermal behaviour could be investigated through a system scale model that captures SOFC internal thermal homogeneity. The leading feature of the modeling strategy was the capability to evaluate the internal distribution profiles of characteristic variables such as hydrogen concentration, current, over-potentials and temperature in the flowsheeting environment. This becomes possible not only at the cell scale but also at stack scale. For instance, Figure 6 (left) depicts the effect of anode tale gas recycling rate on the current distribution in a cell embedded in a short stack. Figure 6 (right) shows the effects of the same operating variable on the stack (4 cells) current and temperature counters presented in 2D including the fuel flow (stack width) direction and stacking (stack height) directions.
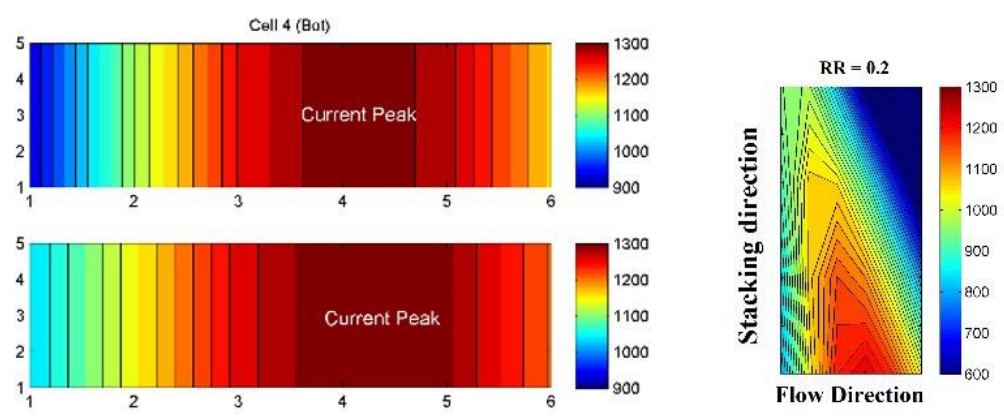

Current Density (A/Cm2)
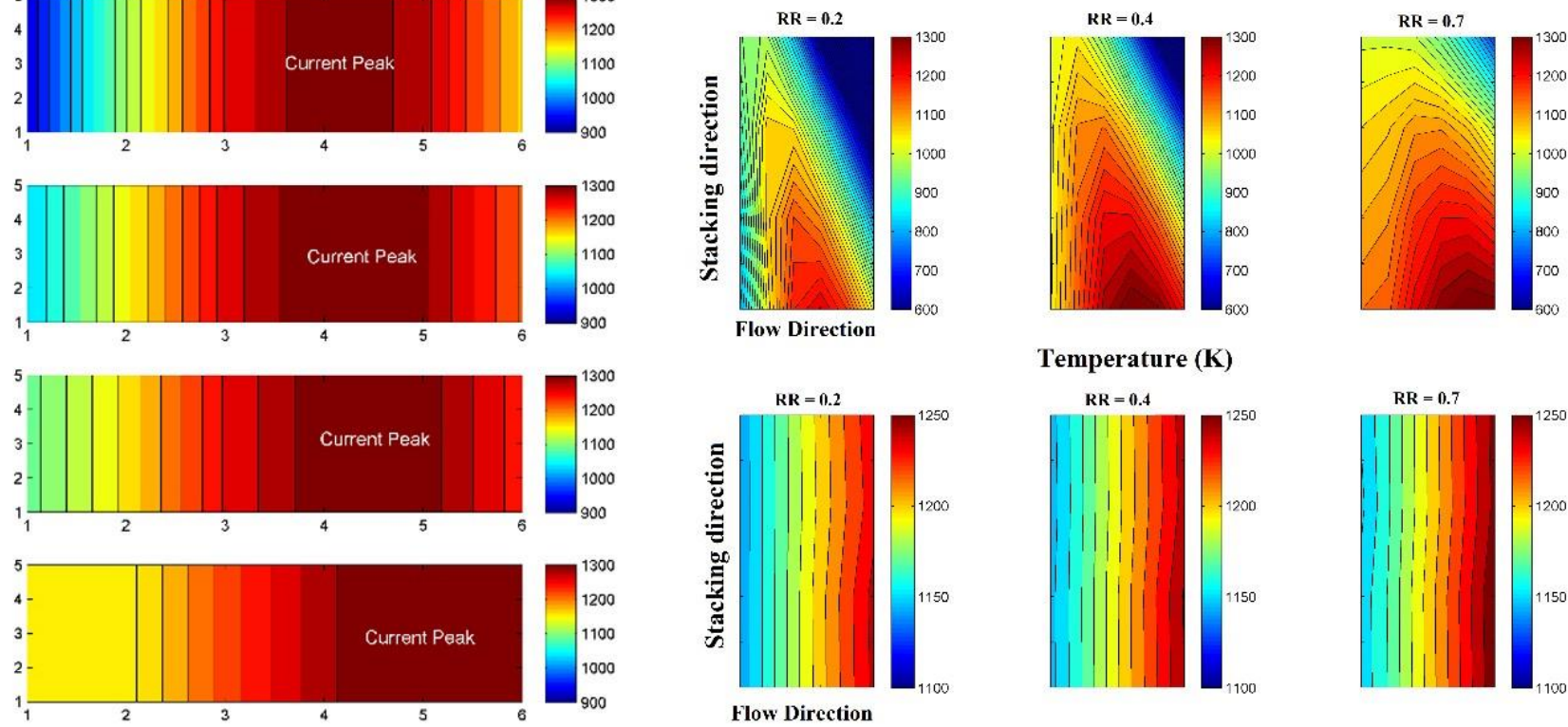

Temperature (K)
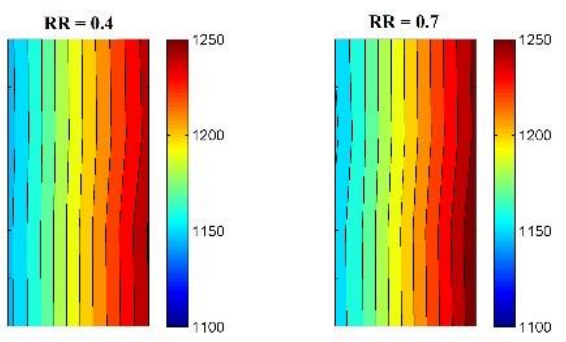

Figure 6 (left) Current distribution in single cell embedded in a short stack. (right) Effects of the same operating variable on the stack (4 cells) current and temperature counters presented in 2D including the fuel flow (stack width) direction $(x)$ and stacking (stack height) direction (y).

Our subsequent work [29] extends the approach to stack and system scales in which we evaluated SOFC (as a 3D geometry) embedded in a system including main BoP units such as the external steam reformer. We and our industrial partner CFCL Ltd. aimed to use the model for the SOFC system thermal management. This becomes feasible owing to the stack features included in the flowsheet for the first time. The model also effectively integrated BoP units demonstrating the flowsheeting environment advantages mentioned earlier. Two case studies were studied for a short stack operating with BoP in system, i.e., the impacts of flow maldistribution in the stack manifold and the depleted fuel recycling on stack thermal inhomogeneity. It was shown that anode gas recycling could be used strategically for managing the gradients within the stack, while also enhancing fuel utilisation and water management. The thermal management challenges and opportunities were further investigated in subsequent work $[20,30]$ in which we sought further operation relevant strategies to improve the SOFC thermal homogeneity. This work resulted in novel opportunities such as enriched air utilisation and also combination of various approaches to achieve optimum results. Note that these opportunities identified using a system level modelingshow that 
the devolving macro scale models and micro scale ones must proceed interactively and in parallel to each other.

Fuel flexibility is an attractive feature of SOFC technology. Due to its high temperature (600$700{ }^{\circ} \mathrm{C}$ ) operation, most of hydrogen carrier fuels, including renewable fuels, can be reformed internally through various chemical pathways such as steam reforming, partial oxidation, etc. In a designed system, however, fuel change is not practical. It may cause several system performance problems, making dynamic fluctuations, control difficulties and undesirable measures that do not meet the design load/voltage requirements. In order to demonstrate the system fuel diversity capabilities, these consequences must be assessed through quantifying the operating measures for a range of fuel and also of potential combinations of fuel. From this viewpoint, the numerical predictive models play a critical role given the experiments cost and limitations of such as large number of possible fuels. This obviously needs a system level model with internal and external fuel reformation capabilities.

In [31], fuel diversity in SOFC systems was evaluated using the system level simulation platform. This paper examined the technical and environmental challenges and opportunities relevant to the potential SOFC fuels with specific focus on promising renewable fuels. The research results were validated using an industrial scale SOFC system published by Pacific Northwest National Laboratory (USA) [32]. The modeling results were based on steady-state operation. The control relevant issues caused by fuel change must be assessed in dynamic mode. The next challenge is to develop the modeling platform as a predictive tool for time-dependent evaluation of internal gradients resulting from the fuel change. Moreover, the impact of this scenario on the SOFC longevity is a crucial aspect to be modelled.

A distributed variable 1D-model of the SOFC was developed [27] in Aspen HYSYS with representation of internal reforming on the anode within the plug-flow reactor (PFR) module of the flowsheet software. The reforming reaction calculations were carried out in the PFR module and the electrochemical details were calculated in the spreadsheet module. By interlinking the two modules, temperature, composition and current density profiles could be readily calculated using empirical correlations and without the necessity of using an external coding platform, such as MATLAB or FORTRAN. Results for different reforming activity were discussed with respect to temperature, current density and concentration profiles, anode oxidation risk and carbon formation potential, all of which impact on performance and/or durability and life. While reduced reforming activity was shown to result in more gradual profiles for current density and temperature compared to fast reforming, such gradual reforming comes at the expense of reduced Nernst voltage and consequently results in a loss of fuel cell efficiency. Figure 7shows that for constant voltage operation gradual or distributed reforming results in a lower average current density compared to fast reforming and therefore leads to a loss in efficiency. 


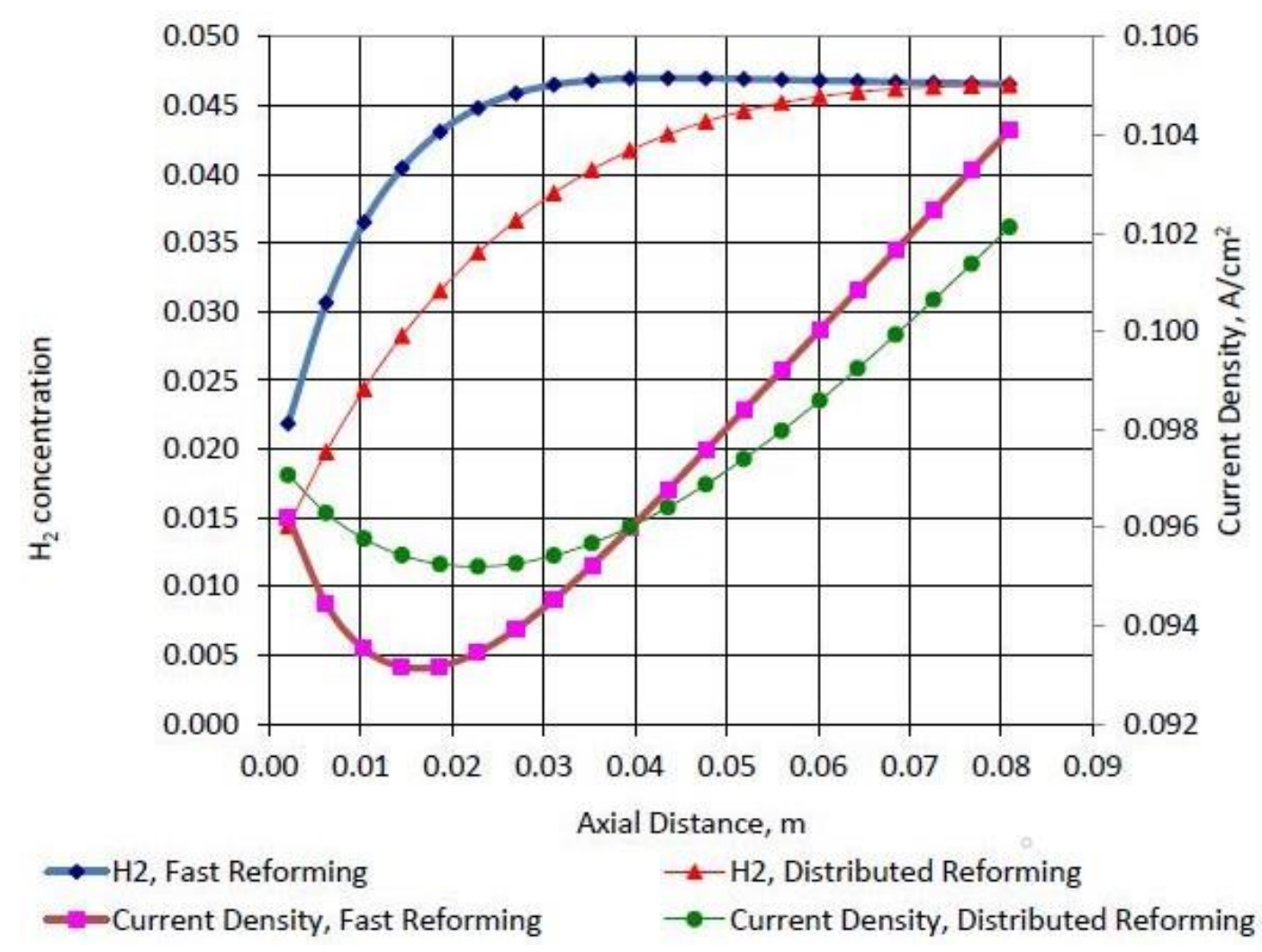

Figure $7 \mathrm{H}_{2}$ and current density profiles for fast and distributed reforming.

At cell scale, the temperature differences between cell elements were simulated in [20] using a pseudo 3D model. The model consists of a four-layer structure including stand, two interconnects, and PEN (Positive electrode-Electrolyte-Negative electrode). A OD model approximated each individual layer. The heating process through the surrounding furnace was considered. The model results show a good agreement with practical data, offering a significant improvement compared to reduced models in which the impact of external heat loss is neglected. Temperatures of the layers were estimated for adiabatic and non-adiabatic operations. This allows capturing the detailed thermal behaviour of a single cell followed by a polarisation loss assessment. Finally, model-based design of experiment was demonstrated. The model was tuned and validated with experimental data from an industrial scale SOFC system manufactured by Ceramic Fuel Cells Ltd.

In an extension to the above work at system level, a modular simulator of dynamic behaviour of the Solid Oxide Fuel Cell (SOFC) system, suitable for use as a training tool was developed [33], as an alternative to expensive practical tests. This simulator, developed in ACM, captures all of the processes in an SOFC module: mass, energy, and charge balances, overpotential losses, ohmic losses and electrochemical reaction kinetics. The developed simulator effectively minimises the requirements of mathematical and programming skills on the part of the user. The ease of application of the simulator was demonstrated through i) steady-state simulation and estimation of the stack's distributed internal variables followed by 1D optimisation and ii) illustration and interpretation of the transient behaviour of the SOFC system. The simulator not only serves as a useful tool for practical applications and as a virtual laboratory, it also opens up opportunities for developing an in-built SOFC simulator module in flowsheet simulation software such as Aspen Plus and Aspen HYSYS. 


\subsection{Electrochemistry, Microstructure and Reaction Kinetics}

\subsubsection{SOFC Electrochemistry}

At a fundamental electrochemistry level, our work [34] demonstrated that accounting for the variation in the reversible potential under closed circuit, along the cell length, as a separate "Nernst loss" allows prediction of the effects of operating parameters. The Nernst losses are attributed to the change in composition of the fuel along the length of the cell. The extent of Nernst voltage loss can be seen in Figure 8 -almost one-third and one-fourth of the total voltage loss at lower (1000$3000 \mathrm{~A} / \mathrm{m}^{2}$ ) and higher $\left(4000-7000 \mathrm{~A} / \mathrm{m}^{2}\right)$ current densities, respectively. The Nernst losses increase with the utilization of oxidant and fuel with respect to all the constituting parameters except the fuel composition, in which case it depends on the inlet concentration of $\mathrm{H}_{2}$. Since the Nernst losses are shown to contribute significantly towards voltage losses, particularly for high temperature fuel cells, it was suggested that they be treated separately from ohmic, activation, and concentration losses in any analysis of voltage losses [22]. This is an important consideration for optimizing cell composition and microstructure in order to reduce ohmic, activation and overpotential losses.

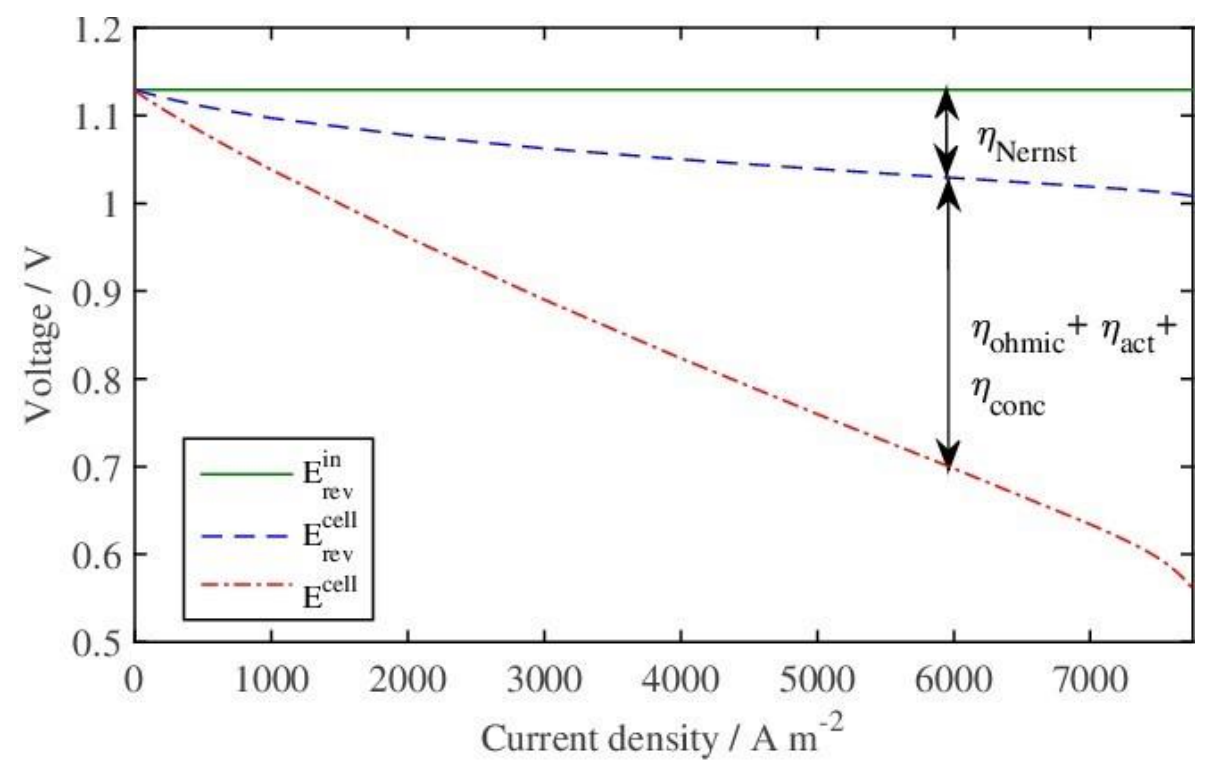

Figure 8 Voltage breakdown for a SOFC at $800{ }^{\circ} \mathrm{C}$ with $97 \% \mathrm{H}_{2}, 3 \% \mathrm{H}_{2} \mathrm{O}$. Breakdown of cell voltage losses accounting for Nernst voltage loss; other voltage losses comprise activation, ohmic and concentration overpotential losses [34].

Fundamental electrochemical modeling provides insights into the electrochemical reaction phenomena that form the core of the fuel cell operation. Primarily, three different types of polarisation affect the cell voltage. The activation polarisation represents the potential lost in overcoming the activation barrier for charge transfer reactions. The most widely used mathematical model for the activation phenomena is the Butler-Volmer (BV) equation.

In general, incorporation of the Butler-Volmer (BV) equation into multi-scale modeling frameworks requires iterative solution of the equation, which is in an implicit form. However, in applications where an iterative solution is not feasible, approximations for the BV equation are generally used to convert it into an explicit form. One particular example will be dynamic models used for controller or observer design. For this purpose, several approximations for the BV equation 
are used in literature like the popular Tafel type equation [35], the hyperbolic sine approximation and the high field approximation [36]. While these approximations are good in limited scenarios [37, 38], a better approximation that can provide wider applicability and lower computational cost is desirable. In our work [39], we presented an improved approximation scheme for the BV equation based on the form $x=f(x)$.

Approximations Proposed Based on Modified BV Equation. The BV equation was modified to the form $x=f(x)$ for deriving approximations. Three forms are discussed as given in the following.

$$
\begin{gathered}
\eta=\frac{R T}{\frac{\alpha_{t o t}}{2} F} \sin ^{-1}\left(\frac{i}{2 i_{0}} \exp \left(\frac{-x F \eta}{R T}\right)\right) \\
\eta=\frac{R T}{\alpha_{1} F} \ln \left[\frac{i}{i_{0}}+\exp \left(\frac{-\alpha_{2} F \eta}{R T}\right)\right] \\
\eta=\frac{R T}{\alpha_{1} F} \ln \left[\frac{i}{i_{0}\left(1-\exp \left(\frac{-\alpha_{t o t} F \eta}{R T}\right)\right)}\right]
\end{gathered}
$$

In these expressions, $x=\alpha_{1}-\frac{\alpha_{t o t}}{2}=\frac{\alpha_{t o t}}{2}-\alpha_{2}$, where $\alpha_{t o t}$ is the sum of the two transfer coefficients. These forms can be used to formulate iterative solution schemes that are shown to perform better compared to the standard form of the BV equation. Alternatively, explicit form approximations for the BV equation can also be constructed by approximating the over-potentials on the right-hand sides of the expressions with standard approximations like the high field or hyperbolic sine approximation.

Performance Comparison. Comparisons of the performance of the proposed forms of the BV equation with traditional approximations and the actual implicit form solution are performed to ascertain the effectiveness of the proposed forms. It was found that the proposed second form of the BV equation performs best with the hyperbolic sine approximation for the right-hand side of the expression.

Some of the results of the comparison of the proposed forms with standard assumptions are presented in Figure 9. Literature studies indicate that generally for $\alpha_{1}>\alpha_{2}$, the more important region is $x>0$. These results along with other results [39] confirm that the second form of the BV equation is the best approximation for the region $x>0$ throughout the $\frac{i}{i_{0}}$ range and for $\frac{i}{i_{0}}>1$ in the $x<1$ region, although it has some small error in the $x<1$ region with $\frac{i}{i_{0}}<1$. 


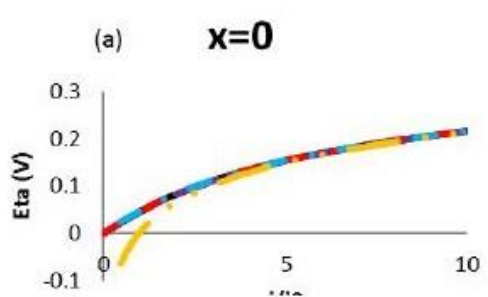

(c) $\quad x=0.8$
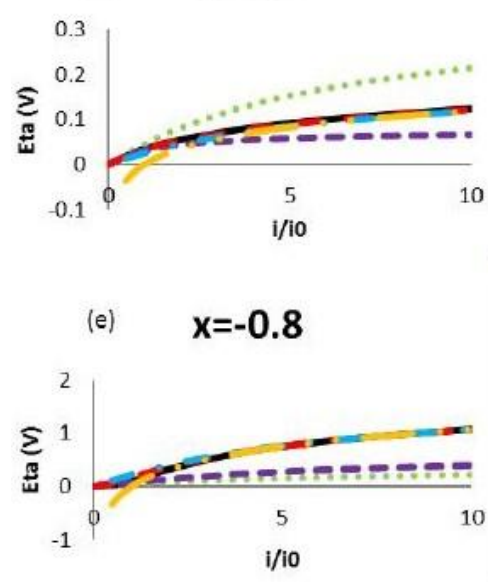

(b) $\quad x=0.4$

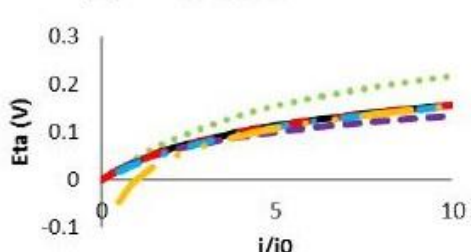

(d) $\quad x=-0.4$
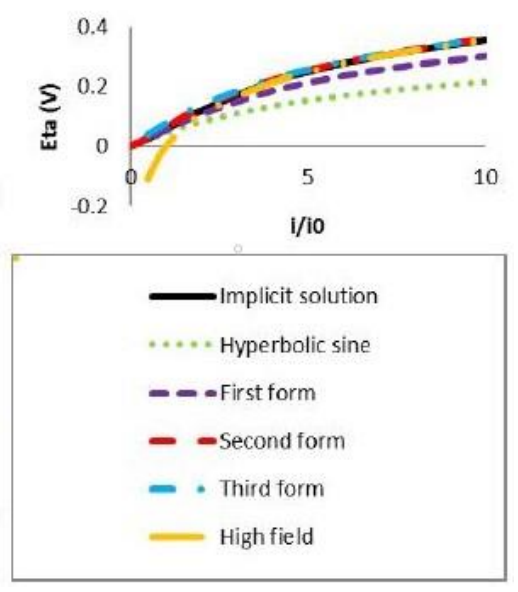

Figure 9 Performance comparison of proposed BV approximation with other common approximations [39].

Convergence Properties with Fixed-Point Iterative Calculations. In addition to enabling better explicit approximations for the BV equation, the proposed forms also enable efficient iterative schemes using the fixed-point theorem. The convergence results for such iterative schemes are reported in detail in [38]. It was found that the second form proposed earlier converges with less than one iteration (for a specified accuracy of 1e-3) throughout the range studied, especially in the range $x>0$ with guaranteed convergence properties.

In effect, the proposed approximation schemes for the BV equation not only provides an explicit expression, but is also useful in formulating better iterative schemes in its implicit form. The proposed iterative algorithm enables ease of implementation, faster computations and elimination of the need for Jacobian information.

\subsubsection{SOFC Electrochemical Reaction Kinetics Modeling}

Our work in this area was focussed on the electrochemical oxidation of hydrogen. Generally, CO electro-oxidation is considered less facile and for modeling it is assumed that CO consumption occurs via the WGS reaction only. Because the stoichiometry of $\mathrm{CO}$ conversion is the same for both routes, this assumption has no effect on mass balance.

Thermodynamic Consistency. Modeling the electrode electrochemical reaction kinetics in the SOFC can be useful for increasing the rate of the overall reaction. The parameters of the reaction kinetic models often need to be estimated from experimental data. Methods for monitoring and generating data include electrochemical impedance spectroscopy, temperature programmed desorption, near-infrared spectroscopy, short-wavelength near-infrared spectroscopy and ultraviolet visible spectroscopy. The fundamental requirement while estimating the parameters is 
the satisfaction of thermodynamic consistency conditions. This was achieved in [37] using constrains that relate the reaction enthalpies and the entropies to the activation energies and the preexponential constants respectively. To achieve this, thermodynamic data for many intermediate species participating in the mechanism are required and these are seldom available. Further, this approach is an overkill if our aim is the estimation of the reaction rate coefficients (excluding preexponential constants and activation energies).

In our work [40], we proposed a thermodynamically consistent formulation of the SOFC Ni/YSZ anode reaction kinetics for the estimating the parameters. The rate determining steps in the mechanism were also identified using the concept of 'degree of rate control'.

We demonstrated that the reaction mechanisms could form loops thereby introducing constraints on the reaction rate constants through the anode reaction mechanism proposed in [37]. The reaction mechanism contains a loop as shown in Figure 10.

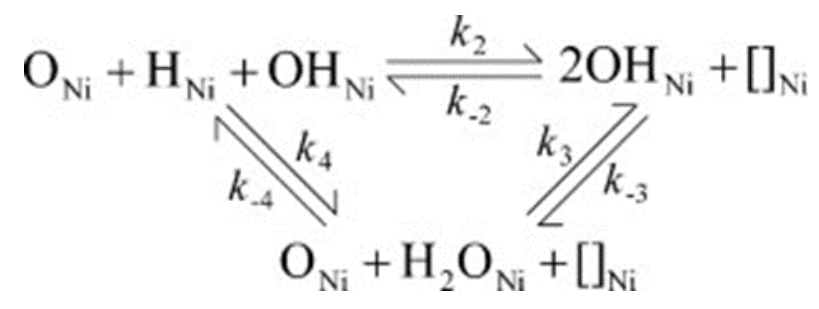

Figure 10 The loop in the SOFC anodic reaction mechanism [41].

Applying the equilibrium conditions, we can obtain the following condition for the rate constants known as the Wegscheider condition [41].

$$
W r=\frac{k_{-2} k_{+3} k_{+4}}{k_{+2} k_{-3} k_{-4}}=1
$$

The reaction rate parameters must satisfy the condition failing which the model will represent a physically impossible system since the equilibrium flux becomes non-zero representing a permanent deviation of concentrations from their equilibrium ratios [41]. This condition was found to be violated using the parameter values estimated in [37].

New Formulation of the Reaction Kinetics Equations. The traditional formulation of the reaction kinetics using law of mass action results in differential equations with the surface coverage as the dependent variables. This formulation does not consider the driving forces of the reactions explicitly. Chemical reactions are driven by the chemical potential difference, the Gibbs free energies being the flow variables. Due to the difficulty in using these quantities, a formulation for the reaction kinetics is developed using the new thermo-kinetic force proposed in [41]. Expressions for the species' capacities are required in the new formulation, which can be calculated from their standard chemical potentials [40]. If this information is not available, any set of equilibrium concentrations can be used as capacities as proven in our paper [40]. It is also shown that this formulation satisfies the De Donder conditions given in the following equation.

$$
\frac{J_{+i}}{J_{-i}}=\exp \left(-\frac{(\Delta G)_{i}}{R T}\right)
$$


Where $J_{+i}$ and $J_{-i}$ are the forward and reverse reaction fluxes and $\Delta G$ is the Gibbs free energy.

Using this new formulation can avoid the detailed thermodynamic consistency tests needed in parameter estimation requiring extensive thermodynamic data. Parameter estimation using this new formulation will also reduce the search space to consistent values thus speed up the searching time. The number of parameters to be estimated is also reduced to half that of the traditional formulation. An iterative algorithm was developed to exploit the new formulation in estimating the reaction rate constants without violating the thermodynamic constraints. More details of the algorithm can be found in our work [40].

The parameter estimation results using the new formulation are presented in the form of frequency response plots [40]. They compare favourably with other estimates [37] and result in a lower least squares error. The difference with experimentally generated data is attributed to the non-inclusion of low frequency processes like diffusion into the model.

Graph based reaction kinetics modelling. Graphs form an intuitive and convenient basis to represent the reaction mechanism networks that allows elegant visualisation of reaction routes leading to the overall reaction. This representation further allows the use of several well-established network analysis methods from other domains like electrical, thermal, mechanical etc. to chemical reaction networks. In our collaborative work with Worcester Polytechnic Institute, we explored the application of reaction route graphs for SOFC reaction mechanism analysis. Theoretical basis for the application of the graph-based method to linear and non-linear chemical reaction mechanisms were established in [42]. An algorithm for utilising the graph theory-based approach to elucidate unknown reaction mechanism was presented in [43].

This graphical approach was applied to analyse the hydrogen oxidation mechanism on the standard Nickel/Yttria-stabilised Zirconia (Ni/YSZ) SOFC anode in our work [44]. This mechanism consisted of surface and charge transfer reactions occurring on the Ni and YSZ surfaces and their interfaces in SOFC anode. The mechanism consisted of 13 reaction steps, 8 intermediate and 5 terminal species as shown in Figure 11.

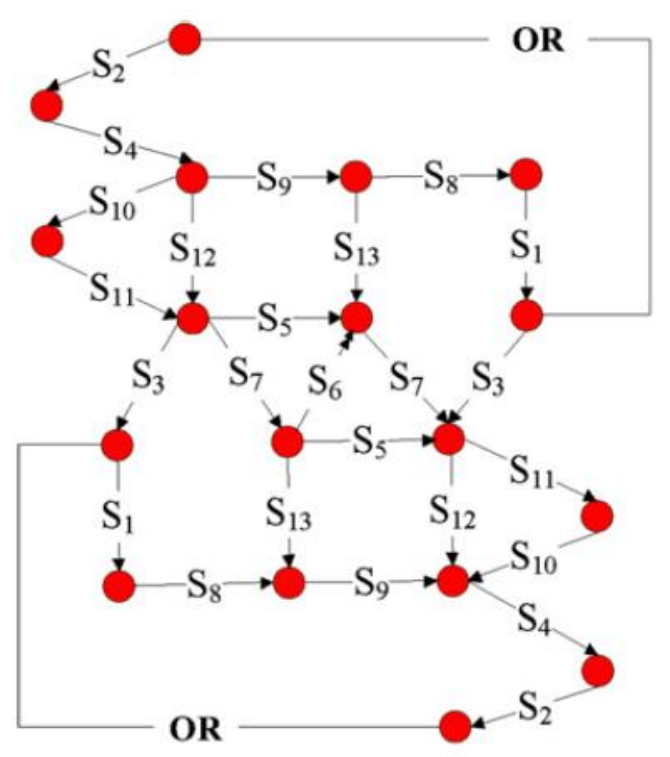

Figure 11 Graphical approach to analyse the hydrogen oxidation mechanism [45]. 
In the reaction route graph for the mechanism, the nodes represent the intermediate states during the reaction progression through a particular path and the directed edges represent the different reaction steps. The OR represents the overall reaction. The graph illustrates the different paths possible to achieve the overall reaction.

$$
H_{2(\text { gas })}+\mathrm{O}_{\mathrm{O} Y S Z}^{\mathrm{x}} \leftrightarrow \mathrm{H}_{2} \mathrm{O}_{\text {(gas) }}+V_{o Y S Z}^{\ddot{*}}+2 e^{-}
$$

The graph is exploited using electrical analogy to identify critical paths and rate limiting steps. Further, expression for the overall reaction rate was derived using quasi steady state assumptions and the graph connections. The rate expression was validated through comparison of polarisation curve with experimental data. This study revealed the dominant pathway to be the one containing the two-hydrogen spill-over reactions. The hydrogen spill-over to oxide ion was identified as the slowest reaction step with the highest resistance governing the rate of the over-all reaction.

\subsubsection{SOFC Electrode Microstructure Modeling}

The SOFC electrodes and electrolyte are the key components where the chemical and electrochemical reactions take place. The microstructure of the electrodes plays a vital role in determining the fuel cell performance. There is ample scope for improving fuel cell performance through optimisation of the cell microstructure. Efforts are underway to devise methods for specific microstructure tailoring [46-49]. Best cell performance can be obtained through a trade-off between electrochemical reactions and species transport processes. Mathematical modeling of the electrode microstructure can offer many benefits for understanding and optimising the microstructure. Our work [50-52] in this area focussed on mathematical modeling of SOFC microstructures.

The analytical models of the electrodes were developed using analytical methods. Principle of coordination numbers and percolation theory formed the basis for these models. In [53], we presented analytical models for the $\mathrm{H}^{+} / \mathrm{e}^{-} / \mathrm{O}^{2-}$ mixed conducting electrodes. The microstructural properties like the triple phase boundaries and the conductivities were presented in nondimensional forms for generalisation and ease of application to different geometries and scales. A recently introduced method for improving fuel cell performance is the preparation of the electrodes through infiltration method [50]. This produces a unique microstructure for the electrodes where the infiltrated element deposits as man-sized particles while the other element forms the backbone (Figure 12). This arrangement of the electrode particles can result in increasing the triple phase areas and thereby resulting in improved performance. In our work [52], we proposed an analytical model for infiltrated electrodes based on percolation theory and coordination principles. The triple phase boundary density of the electrodes is defined in terms of the percolation probabilities, the particle sizes, their volume fractions and porosity. The percolation probabilities were defined based on empirical correlations and were validated with literature data. Several parametric analyses were performed through simulations to facilitate a good understanding of the microstructure. The results were also validated comparing them to the predictions of numerically simulated electrode structures. 


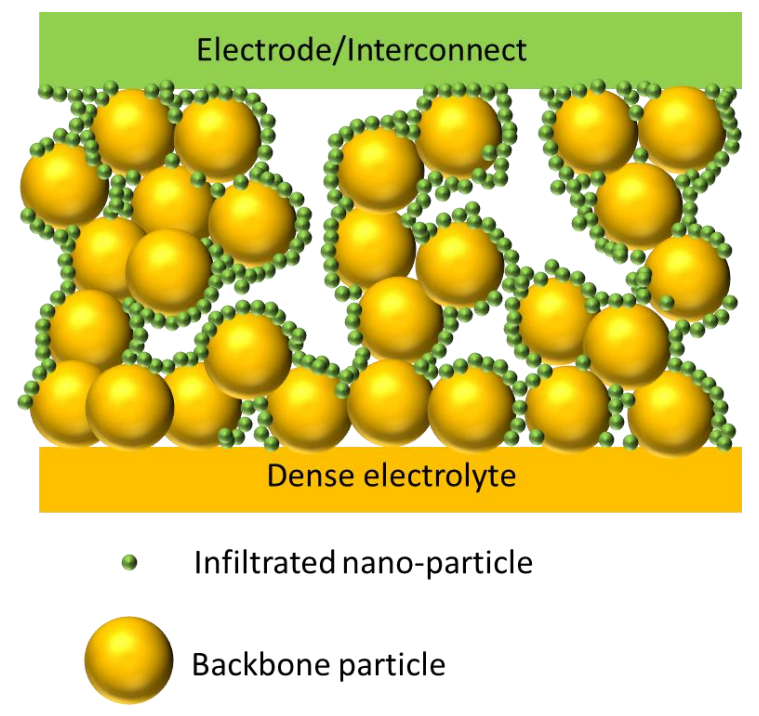

Figure 12 Schematic of an infiltrated electrode with micro-meter sized backbone particles and nanometer sized infiltrated particles [51].

One of the practical uses of microstructural modeling is that it provides an opportunity to study different configurations through simulations with little investment in time and cost. These models can also be incorporated into optimisation routines to search for microstructures that can provide best performance. Since several kinds of microstructures have been introduced for the SOFC electrodes, it is useful to perform optimisation studies on these to perform a comparative analysis. This was the subject of our publication [53], where different microstructure models including the conventional two particle electrodes, two particle infiltrated electrodes, one and two particles based mixed ionic and electronic conducting electrodes, three particle based electrodes and electrodes that change their structure dynamically during operation were all validated using data from literature and comparative optimisation studies were presented. This study resulted in offering insights into the influence of microstructure parameters on microstructural properties. The plots of TPB density surfaces as functions of particle sizes and volume fractions revealed that infiltration modifies the symmetrical behaviour of the triple phase boundary density (exhibited in conventional electrodes) from which we can understand the importance of proper selection of microstructure parameters to achieve best cell performance.

\subsection{Control, Monitoring, Diagnostics and Optimisation}

\subsubsection{SOFC Model Validation}

With wide availability of computing power, model-based design and analysis methods are gaining more and more ground in science and engineering. Mathematical models can be very useful for enhancing understanding and exploring the design space at reduced cost and time. However, the models will have to be rigorously validated with data for providing sufficient confidence in their predictions. This important step of model validation is often neglected resulting in lesser model usability.

SOFC modeling involves representation of several processes that have significant uncertainties as the underlying mechanisms of electrochemical reactions are not fully understood. Model validation is approached from several viewpoints in the literature. Methods applied for model 
validation include classical statistics, Bayesian methods and artificial intelligence methods. In our work [54], we enumerated a classical statistics-based model calibration and validation strategy for a cell level, lumped parameter SOFC model. Our work was concerned with the steady state validation, but the concepts can be applied to other model types. For example, dynamic validation can be approached as a special case with space and time dependent variables. However, data generation at faster sampling times are required to validate dynamic models.

For the model validation strategy presented in our work [54], several quantitative methods like statistical hypothesis testing, sensitivity analysis and design of experiments are employed along with the expert knowledge of the physical and chemical fuel cell process. Two specific types of model errors are identified, viz., model structural errors and model parametric errors. The validation strategy deploys two stages. In the first stage, the model structural errors are identified employing knowledge-based interpretation of model response to change in operating inputs. This stage involves application of quantitative methods like the design of experiments but also depends on qualitative knowledge-based interpretation of results. In the second stage, model parameter calibration is carried out using various quantitative methods to address the parametric errors. Figure 13 illustrates various stages in the proposed validation strategy, where the blue region represents the first stage of validation.

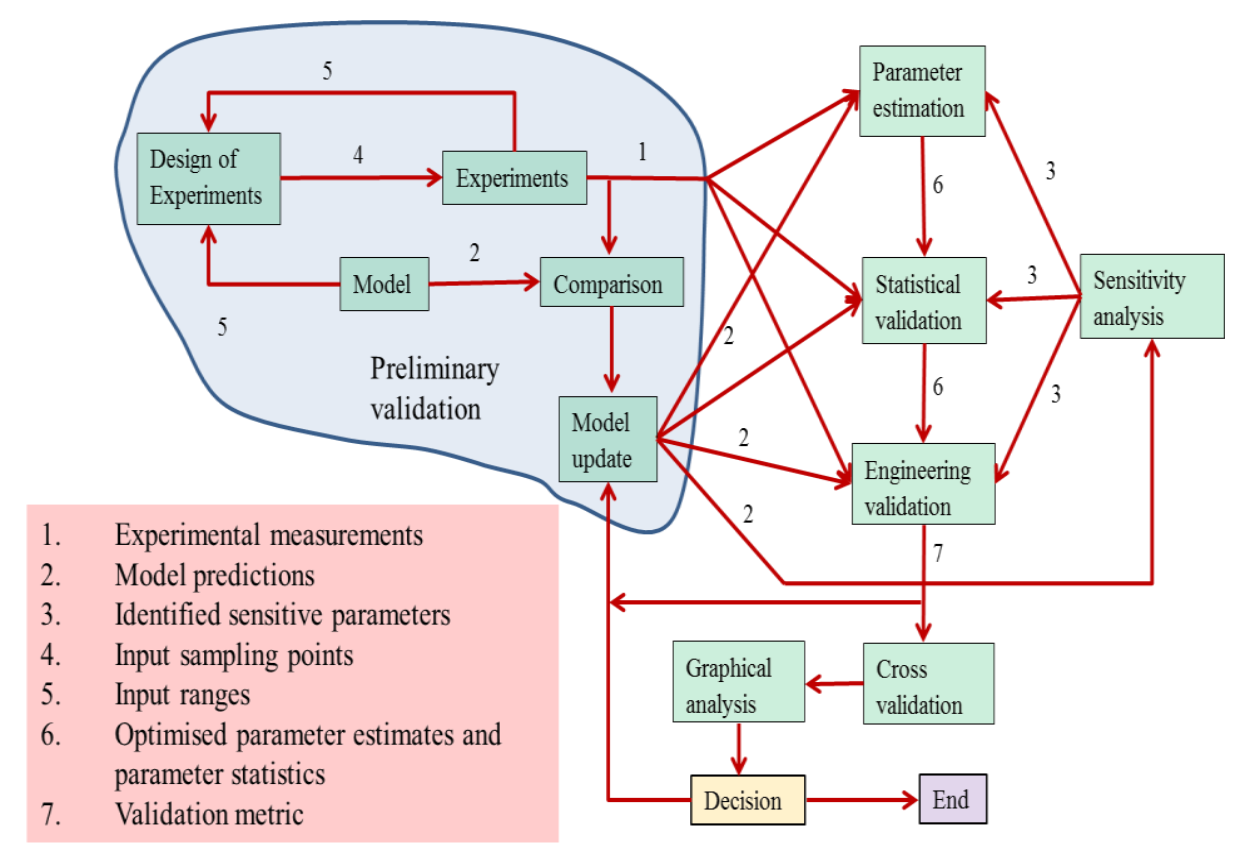

Figure 13 Flowchart for the two-stage model validation [54].

The data for model validation were generated through custom designed experiments on an SOFC test rig in collaboration with Ceramic Fuel Cells Limited. The experiments were aimed at generating data to cover the design space consisting of the SOFC operating range. In order to limit the number of runs, the experiments are designed using Latin hypercube sampling plan with the additional criteria of maximising the minimum distance between the points. This experimental design methodology will help to cover the design space and obtain random samples. The source of voltage error between the measured and the model predicted data is rigorously analysed considering all possible causes as shown in the fish bone diagram in Figure 14. Once the responsible model structural error is identified and amended, the second phase of the validation is performed. 


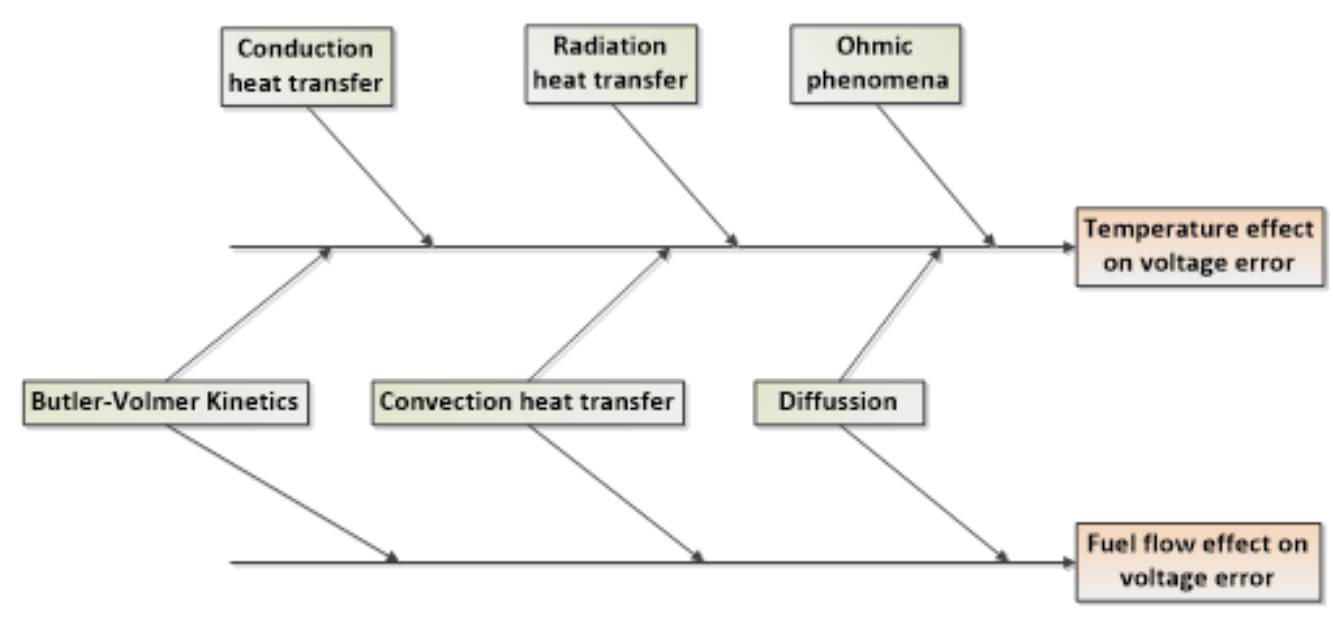

Figure 14 Fishbone diagram for root cause analysis of voltage error [54].

The data for model validation were generated through custom designed experiments on an SOFC test rig in collaboration with Ceramic Fuel Cells Limited. The experiments were aimed at generating data to cover the design space consisting of the SOFC operating range. In order to limit the number of runs, the experiments are designed using Latin hypercube sampling plan with the additional criteria of maximising the minimum distance between the points. This experimental design methodology will help to cover the design space and obtain random samples. The source of voltage error between the measured and the model predicted data is rigorously analysed considering all possible causes as shown in the fish bone diagram in Figure 14. Once the responsible model structural error is identified and amended, the second phase of the validation is performed.

For the second stage of the validation, data on SOFC model parameters are collected and statistically analysed for uncertainties. The electrochemical parameters were found to have the most uncertainty as expected. The elementary effects-based screening of the parameters helped in identifying the most sensitive ones. Model parameter statistics were derived from the data using least squares estimation. The model is then calibrated and validated using hypothesis testing resulting in model acceptance with less $8 \%$ maximum error in predicting the cell current.

\subsubsection{Control Structure Design}

Even the basic operation of the SOFC requires a control system to regulate the flows, fuel utilisation, temperature and voltage. Although sophisticated control schemes are possible, simple PID controllers in separate loops are the simplest, easily implemented and most commonly employed control structures in SOFCs. In such a linear multi-loop control structure design, careful attention is needed in their design due to the possible interaction s between the loops. In addition, SOFCs can be operated in several operating modes depending on their applications.

Depending on the application, three different operating modes with respect to control are identified for the SOFC. They are the a) constant fuel utilisation and temperature operation, b) constant voltage and temperature operation and c) constant temperature and power tracking operation modes. The input variables that can be manipulated include the fuel and air flows and the cell current. With these set of manipulable variables, controlled variables and operation modes, 18 different multi-loop control structures are possible. All these control structures were evaluated through a process interaction analysis for effective control structure design in our work [55]. The 
choice of analysis method was the frequency dependent relative gain array (RGA) to account for the process dynamics. The best control structures were then used to design PID controllers and their control performance was evaluated. Due to the presence of minimum interactions, a model predictive controller designed for these control structures also provided superior performance compared to control structures with large loop interactions. The results of this study provide guidelines for the selection of manipulated and control variables and designing effective control structures for plant-wide control of the SOFC system.

\subsubsection{Monitoring}

SOFC technology has advanced significantly during the last decade. However, it has yet to meet all durability and lifetime requirements that will enable it to be competitive against existing and other competing technologies. There is a lot of scope for improving SOFC durability by solving materials related issues. Yet another avenue for improving the cell durability is through effective operational management by continuous and online monitoring of critical variables so that incipient failures can be detected and rectified in a timely manner.

One of the important quantities that can indicate the health of the SOFC are the thermal profiles inside the cell. Excessive thermal gradients can indicate failures or abnormalities in the cell or other components connected to the cell (for example fuel and air supply, electrical load etc.). Due to several practical difficulties, the cell's internal thermal gradients are not available for in-situ measurement. In this context, online estimation of the internal thermal profiles in the SOFC can be very useful in the overall monitoring and diagnostic scheme.

We had presented a non-linear model based adaptive observer for estimating the internal thermal profiles of the SOFC in [56]. The dynamic model is formulated based on the concepts of tank in series reactor with six lumps to capture the dynamic spatial temperature profiles. Simulations establish good tracking ability of the adaptive observer. Comparisons with a linear Luenberger observer also establish its superior tracking performance. This non-linear observer offers advantages of requiring fewer measured variables, validity over a wide range of operating conditions and robustness to fluctuations in inlet flows.

In a later work [57], the adaptive observer was extended to estimate the inputs in addition to the states as an unknown input observer that simultaneously estimates the states and the inputs of the SOFC. In this case, the cell current and fuel and air inlet temperatures were considered as slowly varying parameters that need to be estimated in addition to the anodic and cathodic inlet flows.

Details of the observer stability proof using non-linear theory can be found in [56]. Simulations established the input and state tracking abilities of the observer. Figure 15 shows the response of the adaptive parameters that are estimated online during a step change in current density. Besides offering the same advantages as the previous adaptive observer, this unknown input observer can robustly handle disturbances to be SOFC input variables effectively and provide accurate estimates of the cell internal thermal profiles. 


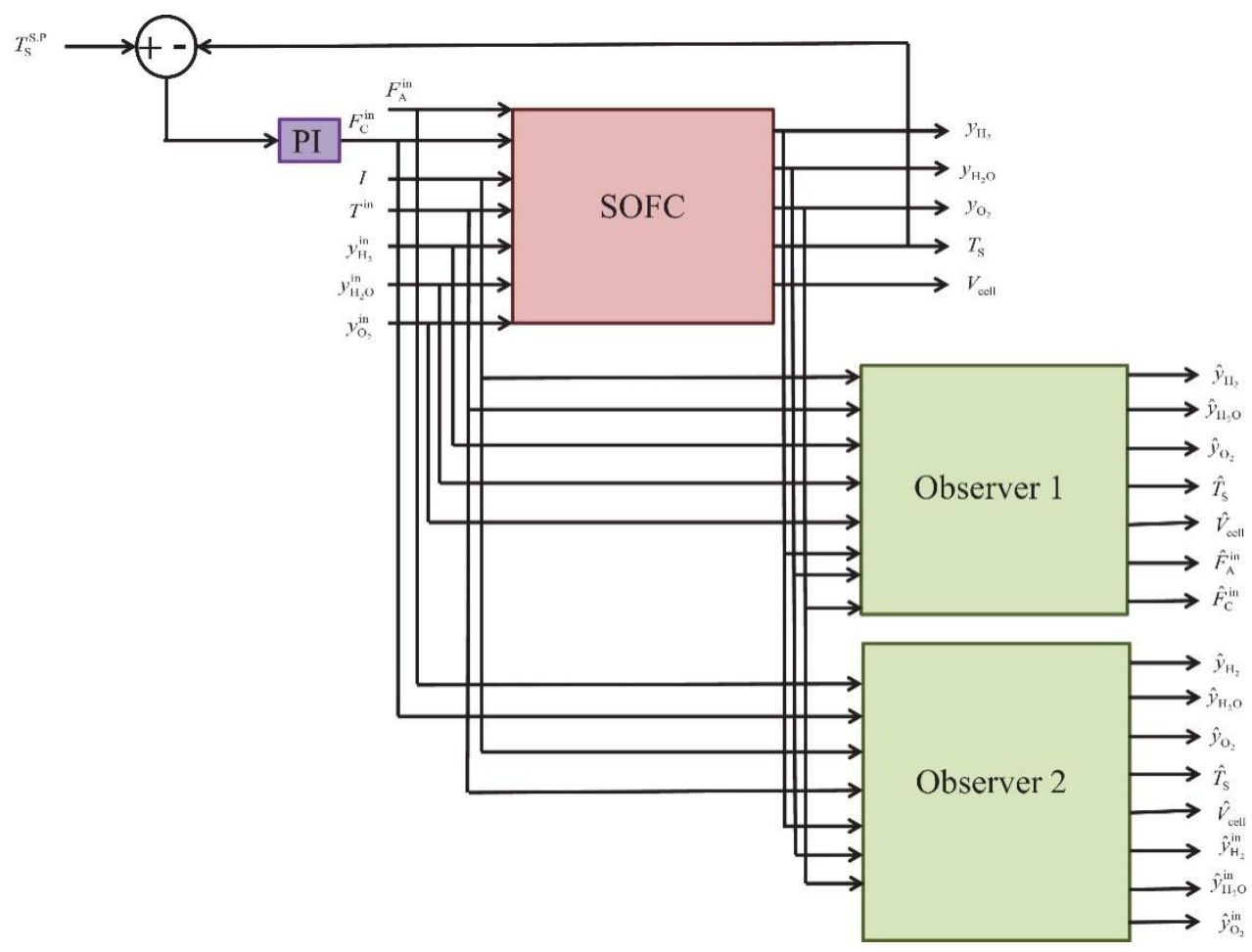

Figure 15 Schematic depiction of the multiple adaptive observer-based fault identification approach [36].

\subsubsection{Fault Diagnosis}

The SOFC is susceptible to a number of faults in the cell that lead to reducing its general reliability. A monitoring system can indicate some abnormal situation arising in the cell. Due to the complex interactions in the fuel cell, identification of the specific root cause of a fault requires a diagnostic system. The diagnostic system should be capable of isolating different causes for the observed symptoms and give an indication of the root cause for action. Due to the complexity of the fuel cell system with many interactions, a model-based approach is well suited. We proposed a multiple observer-based approach to the problem of SOFC diagnosis in [36]. Five common faults affecting the SOFC (given in Table 1) were simulated in this work. In the Table, $\alpha$ is the loss factor, which is a multiplicative variable imposed on the overall irreversible voltage to simulate the fault. Two different adaptive non-linear observers were designed targeting specific faults.

Table 1 Details of the SOFC fault simulation [36].

\begin{tabular}{llll}
\hline Fault name & Description & $\begin{array}{l}\text { Corresponding } \\
\text { variable }\end{array}$ & Fault simulation steps \\
\hline Fault 1 & Fuel leak & $Q_{A}^{\text {in }}\left(\mathrm{mL} \mathrm{min}^{-1}\right)$ & $-50 \mathrm{~mL} \mathrm{~min}^{-1}$ \\
Fault 2 & Air leak & $Q_{C}^{\text {in }}\left(\mathrm{mL} \mathrm{min}^{-1}\right)$ & $-500 \mathrm{~mL} \mathrm{~min}^{-1}$ \\
Fault 3 & Anode inlet composition & $y_{H_{2}}^{\text {in }}$ & -0.1 \\
Fault 4 & Cathode inlet composition & $y_{O_{2}}^{\text {in }}$ & +0.1 \\
Fault 5 & Cell fault & $\alpha$ & +0.2 \\
\hline
\end{tabular}


Detailed stability proofs for these observers can be found in [36]. Following the successful evaluation of the observer performances, they were tested for fault diagnostic application. The schematic of the proposed fault diagnostic approach is shown in Figure15.

A fault diagnosis strategy is formulated based on the simultaneous application of the two adaptive observers. The observer performance, both for designed and out of the design conditions is presented in Table 2. The symbol 'ü' in the table indicates that the observer estimation is same as the measured value resulting in zero residual and the symbol ' $\hat{u}$ ' indicates non-aero residual. The symbol ' $x$ ' means simulation failing due to unrealistic values. Fault diagnosis is based on the ability of the two observers to track the changes in operating conditions which is monitored through the residual. In general, if an observer reports at least one non-zero residual with the other observer correctly estimates all variables; the fault indicated by the second observer is the root cause of the problem. The cell fault (Fault number 5 ) is the root cause if both observers provide at least on nonzero residuals. More details about these and the detailed simulation studies can be found in [36].

Table 2 Observer tracking performance under different fault scenarios[36].

\begin{tabular}{|c|c|c|c|c|c|c|c|c|c|c|c|c|c|}
\hline \multirow[t]{2}{*}{ Faults } & \multicolumn{6}{|c|}{ Observer 1} & \multicolumn{7}{|c|}{ Observer 2} \\
\hline & $y_{H_{2}}$ & $y_{O_{2}}$ & $V_{\text {cell }}$ & $T_{S}$ & $F_{A}^{\text {in }}$ & $F_{C}^{\text {in }}$ & $y_{H_{2}}$ & $y_{O_{2}}$ & $V_{\text {cell }}$ & $T_{S}$ & $y_{\mathrm{H}_{2} \mathrm{O}}^{\mathrm{in}}$ & $y_{H_{2}}^{\text {in }}$ & $y_{O_{2}}^{\text {in }}$ \\
\hline 1 & ü & $\ddot{u}$ & $\ddot{u}$ & $\ddot{u}$ & $\ddot{u}$ & ü & $\ddot{u}$ & ü & $\hat{u}$ & $\hat{u}$ & $\hat{u}$ & $\hat{u}$ & ü \\
\hline 2 & ü & $\ddot{u}$ & $\ddot{u}$ & $\ddot{u}$ & $\ddot{u}$ & ü & $\ddot{u}$ & $\ddot{u}$ & $\hat{u}$ & $\ddot{u}$ & $\ddot{u}$ & $\ddot{u}$ & $\hat{u}$ \\
\hline 3 & $\ddot{u}$ & ü & $\hat{u}$ & $\hat{u}$ & $\ddot{u}$ & û & $\ddot{u}$ & ü & $\ddot{u}$ & ü & $\ddot{u}$ & $\ddot{u}$ & $\ddot{u}$ \\
\hline 4 & $x$ & $x$ & $x$ & $x$ & $x$ & $x$ & ü & ü & $\ddot{u}$ & ü & ü & ü & ü \\
\hline 5 & ü & $\ddot{u}$ & û & $\hat{u}$ & $\ddot{u}$ & ü & $\ddot{u}$ & $\ddot{u}$ & $\hat{u}$ & û & $\ddot{u}$ & ü & ü \\
\hline
\end{tabular}

No human, animal or plant subjects were involved in the any of the studies that comprise this technical report.

\section{Discussion}

SOFC modeling is of fundamental importance in the on-goingdevelopment/improvement and successful mass-scale deployment of SOFC-based combined heat and power systems, auxiliary power units and other SOFC-based systems. Optimisation of system operating conditions requires reliable models at the system scale. This can be done at $\mathrm{OD}$ or $1 \mathrm{D}$ levels by simulating for different stack performance parameters which will vary over the useful life of the stack.

Understanding stack failure modes and their causes require thermo-mechanical-electrical models of stacks in 3D configuration. Simulation of ageing and degradation caused by impurity poisoning of electrodes and catalysts e.g. for internal reforming, requires detailed kinetic and mechanistic models at the cell level. Modeling for monitoring and control is another area which is of vital importance but is fraught with the challenges of integrating performance variables and their time-based changes in system i.e. BoP-components with those of the myriad of stack components 
- electrodes, electrolyte, contact layers, compliant layers, poisoning guards, interconnects, current collectors and interfaces with BoP components. Incorporating the effects of thermal cycling is an additional challenge.

At the cell and stack level, detailed models identifying the dominant modes of degradation at different stages of life followed by development of appropriate mitigation strategies is a key requirement for the commercial success of the SOFC.

High efficiency SOFC are invariably of the internal reforming type with conversion of methane on the anode and anode chamber via the steam reforming reaction through upgrading the fuel with the heat produced by the electrochemical oxidation of hydrogen [58]. The reforming reaction plays a key role in the performance of the SOFC at all levels - cell performance; stack thermal gradients and stress; and system level steady-state and dynamic performance. Any changes occurring during the operational life of the SOFC system that can have a significant impact on the internal reforming reaction, will consequently not only affect the electrical efficiency, it will also affect stack durability. Therefore, it is important to determine the effect of anode degradation on the kinetics of internal reforming which consequently reduces the efficiency of the system. Ageing and degradation occur from a number of processes which include coarsening of Ni particles due to sintering, particularly at high fuel utilization, and poisoning by contaminants present in the stack materials (e.g. seals) or carried through by the fuel stream over a period of time. Both of which can significantly reduce the kinetic rate of the steam reforming reaction, as known from the petrochemical industry.

The internal reforming kinetics plays a significant role in the cell and stack's temperature, concentration, current density, and voltage profiles during steady and transient operation and consequently, influences the durability of the SOFC stack. Reforming kinetics on an aged anode can be significantly different than on a fresh anode or an early-life anode. There are several SOFC models in the literature for internal reforming SOFCs, which include kinetics of methane reforming derived from empirical correlations, based on data from fresh catalysts. However, there is no reported work in the open literature on reforming on an aged or degraded anode. With changes occurring on the anode during its operating lifetime, and the potential impact on internal reforming kinetics, there is little value in developing detailed models for cell and stack performance. This is also the case for thermal stress modeling of stacks or for developing control algorithms for steady-state and dynamic operation of systems, based on internal reforming kinetics which may not be applicable for anodes that have aged and degraded from prolonged operation under varying operating conditions including thermal cycling.

Degradation also is caused by an increase in ohmic resistance due to formation of dielectric layers between cell and stack components. Cross-leaks and external leaks resulting from seal failure also contribute to degradation. None of these can be avoided completely and can influence the kinetics of the internal reforming reaction.

Mathematical modeling is used as a tool for detecting undesirable gradients in temperature and current density profiles within the cell and for predicting hot-spot locations and high current density points. The fidelity of mathematical modeling of the SOFC system relies largely on the adequate representation of the internal reforming chemistry and kinetics. It is desirable to develop a macromicro kinetic model of the SOFC anode accounting for transport processes and the changing reforming kinetics. The main objective of such modeling work is to create a platform for stack and system level modeling accounting for the influence of anode degradation and ageing on internal 
reforming kinetics with the purpose of creating more reliable models for predicting the performance of real stacks and systems.

The reliability and thus commercial viability of the SOFC technology must be demonstrated at system scale in order to achieve commercial success. Therefore, during the past decade SOFC system level modeling has been increasingly receiving attention by researchers and industries due to its importance in solving the commercialisation relevant challenges. However, in order to make future models more efficient, computational tools for achieving fundamental insights and technical applications need to be target-oriented focusing on the state-of-the-art research gaps as follows:

1) Advances have been made to reduce time-based degradation to a level that has the potential of making the technology commercially viable [59], predominantly through materials science improved protective coatings and scavenger compounds for poisons. However, fuel cell lifetime and reliability is still a barrier to its commercialisation. Practical degradation tests, in particular, at system scale, are complicated, costly and time-consuming. Thus, multiscale models capable of capturing the fuel cell degradation features against dominant factors such as fuel impurities and thermal gradients are in high demand. It is of particular interest to estimate the degradation rate imposed by the balance-of-the-plant components such as the heat exchanger and burner. Due to the lack of knowledge in the interacting mechanisms involved in the SOFC degradation, a comprehensive physics-based model is currently not possible. Utilisation of Artificial Intelligence methods is a prospective solution for this problem given the availability of large data sets that have been generated in large demonstration projects worldwide.

2) Most of the models developed for process control purposes are $O D$ and mostly for the singlevariable-single-objective control design. Smart control design is possible through distributed and dynamic models developed for multi-variable-multi-objective control design projects. This is important as several dominant variables and interacting mechanisms are involved in a SOFC system and its operation that must not be compromised in an optimised control system.

3) The stack design challenges can be addressed by models that capture the stack hydrodynamics as well as the inhomogeneous performance in different layers of the stack. The reduction in efficiency and longevity due to stacking is an important issue in SOFC scale up as it demands multidisciplinary modeling in which chemical, mechanical, and electrical design aspects are taken into account.

It is clear that significant knowledge gaps still exist in understanding the interactions between stack and BoP that lead to substantial performance loss and/or catastrophic stack failures. Detailed analysis of large data sets from field test units are required for developing a thorough understanding of these issues and their impact on stack performance and stack durability [60]. This understanding will be critical in defining optimum control strategies for the system, that ensure reliable and longterm operation of the system. Validated dynamic models are required to address this knowledge gap.

In addition, degradation and sudden stack failures are key areas where more focused investigations are required to arrive at a commercial SOFC product. However, apart from lifetime and system reliability, cost reductions and improved manufacturability are further key requirements for a commercial success of the technology.

However, apart from lifetime and system reliability, further cost reductions, improved manufacturability and reduced installation complexity are key requirements for a commercial success of the technology [61]. 
Materials R\&D is one critical approach to push fuel cells into commercialisation. Material selection holds the key to lifetime and costs. The focus needs to be on materials for improved performance yielding to smaller, more compact fuel cells and more robust SOFC stacks, and replacement of expensive materials for cheaper ones wherever possible. For example, recent progress in lifetime and performance of stainless-steel supported cells operating below $650^{\circ} \mathrm{C}[62$ 63] could represent a step change towards simpler and smaller stack designs and therefore substantial cost reductions. Combinatorial methods combined with fast materials screening techniques are increasingly used in the difficult task to find new materials and improve existing ones. Materials used in fuel cells commonly have to satisfy multiple functionalities and the mathematical methods are ideally suited for defining the path to performance improvements.

Numerous detailed studies on cost reduction drivers of SOFC systems have been carried out, for example the US Department of Energy Study [64].

Reduced complexity of the integrated products (part count reduction) and volume manufacturing with high yield and uniform high quality are key in the strategy to arrive at commercially viable fuel cells. Like with any other commercial technology, product manufacturing volume with high yield significantly influences product costs, and uniform high-quality components are necessary for reliability and life. This is of critical importance for fuel cells, which are largely serial devices, where one low performing component determines the performance of the fuel cell stack. Fuel cells designed for manufacture, automated streamlined manufacturing processes, efficient supply chains, and use of common components will be key goals for achieving commercial success. Extensive experience with Technology Learning Curves for other technology products gives us excellent guidelines for extrapolation of installed costs of SOFC systems with increased volume, and according to the US Department of Energy study, SOFC systems have an excellent change to achieve commercial targets.

\section{Conclusions}

Over the past 15 years our team has engaged in research and development activities in many of the areas discussed above, a summary of which is provided in this technical report. Our work also highlighted the areas where more focussed work is required.

The authors hope that this technical report will be a useful complimentary source for initiating further work in SOFC research as well as provide an exposé of the contributions of our group to this area over the past 15 years.

Notations

\begin{tabular}{|c|c|}
\hline$e^{-}$ & Electron \\
\hline$E$ and $V$ & Voltage (V) \\
\hline$F$ & $\begin{array}{l}\text { Mole flow rate }\left(\mathrm{mol} \mathrm{s}^{-1}\right) \text { (appears in table } 2 \text {, but it is the same symbol as for Faraday's } \\
\text { constant) }\end{array}$ \\
\hline$F$ & Faraday's constant $\left(96485 \mathrm{C} \mathrm{mol}^{-1}\right)$ \\
\hline$\Delta \mathrm{G}$ & Gibb's free energy $\left(\mathrm{J} \mathrm{mol}^{-1}\right)$ \\
\hline$i$ & Current density $\left(\mathrm{A} \mathrm{m}^{-2}\right)$ \\
\hline$i_{0}$ & Exchange current density $\left(\mathrm{A} \mathrm{m}^{-2}\right)$ \\
\hline
\end{tabular}




$$
\begin{array}{lll}
\mathrm{J} & & \text { Reaction flux }\left(\mathrm{mol} \mathrm{min}^{-1}\right) \\
k & & \text { Reaction rate constant } \\
Q & & \text { Volume flow rate }\left(\mathrm{mL} \mathrm{min}^{-1}\right) \\
& & \text { Ideal gas constant }\left(\mathrm{J} \mathrm{mol}^{-1} \mathrm{~K}^{-1}\right) \\
& R & \text { Temperature }(\mathrm{K}) \\
T & \\
y & \text { Species mole fraction }
\end{array}
$$

Greek letters
$\alpha \quad$ Charge transfer coefficient
$\eta \quad$ Overpotential (V)
$\omega \quad$ Weight factor

Abbreviations

$\begin{array}{ll}\text { ACM } & \text { Aspen Custom Modeler } \\ \text { ADL } & \text { Anode Diffusion layer } \\ \text { BoP } & \text { Balance of Plant } \\ \text { BV } & \text { Butler-Volmer } \\ \text { FU } & \text { Fuel Utilisation } \\ \text { MSR } & \text { Methane Steam Reforming } \\ \text { PEN } & \text { Positive electrode-Electrolyte-Negative electrode } \\ \text { RMTN } & \text { Reverse Methanation } \\ \text { SOFC } & \text { Solid Oxide Fuel Cells } \\ \text { TSR } & \text { Tank in Series Reactor } \\ \text { WGS } & \text { Water-gas Shift }\end{array}$

\section{Acknowledgments}

The authors acknowledge the contribution of staff at Curtin University, Ceramic Fuel Cells Ltd and Aston University that have technically supported this work.

\section{Author Contributions}

The contribution of each author is in the order of author names on page 1.

\section{Competing Interests}

The authors have declared that no competing interests exist.

\section{References}

1. Payne R, Love J, Kah M. Generating electricity at $60 \%$ electrical efficiency from $1-2$ kWe SOFC products. ECS Trans. 2009; 25: 231. 
2. Powell M, Meinhardt K, Sprenkle V, Chick L, McVay G. Demonstration of a highly efficient solid oxide fuel cell power system using adiabatic steam reforming and anode gas recirculation. J Power Sources. 2012; 205: 377-384.

3. Langnickel $H$, Rautanen M, Gandiglio M, Santarelli M, Hakala T, Acri M, et al. Efficiency analysis of 50 kWe SOFC systems fueled with biogas from waste-water. J Power Sources Adv. 2020; 2: 100009.

4. Lanzini A, Ferrero D, Papurello D, Santarelli M. Reporting degradation from different fuel contaminants in Ni-anode SOFCs. Fuel Cells. 2017; 17: 423-433.

5. Papurello D, Lanzini A, Leone P, Santarelli M, Silvestri S. Biogas from the organic fraction of municipal solid waste: Dealing with contaminants for a solid oxide fuel cell energy generator. Waste Manag. 2014; 34: 2047-2056.

6. Papurello D, Chiodo V, Maisano S, Lanzini A, Santarelli M. Catalytic stability of a Ni-Catalyst towards biogas reforming in the presence of deactivating trace compounds. Renew Energ. 2018; 127: 481-494.

7. Inac S, Unverdi SO, Midilli A. A parametric study on thermodynamic performance of a SOFC oriented hybrid energy system. Int J Hydrog Energy. 2019; 44: 10043-10058.

8. Barrett S. Wärtsilä SOFC using landfill gas passes first phase field trial. Fuel Cells Bull. 2010; 2010: 5-6.

9. Hosseini S, Ahmed K, Tadé MO. CFD model of a methane-fuelled single cell SOFC stack for analysing the combined effects of macro/micro structural parameters. J Power Sources. 2013; 234: 180-196.

10. Ahmed K, Foger K. Kinetics of internal steam reforming of methane on Ni/YSZ-based anodes for solid oxide fuel cells. Catal Today. 2000; 63: 479-487.

11. Hosseini S, Danilov VA, Vijay P, Tadé MO. Improved tank in series model for the planar solid oxide fuel cell. Ind Eng Chem Res. 2011; 50: 1056-1069.

12. Ravussin F, Van herle J, Autissier N, Molinelli M, Larrain D, Favrat D. Local current measurement in a solid oxide fuel cell repeat element. J Eur Ceram Soc. 2007; 27: 1035-1040.

13. Danilov VA, Vijay P, Tadé MO. Improved tank in series reactor model for tubular solid oxide fuel cell stacks. Chem Eng Technol. 2011; 34: 737-745.

14. Sundén B, Faghri M. Transport Phenomena in fuel cells (Development in heat transfer). Boston: WIT Press; 2005.

15. Bove R, Ubertini S. Modeling solid oxide fuel cells. Berlin: Springer; 2008. p.207-p.239.

16. Inui $\mathrm{Y}$, Ito $\mathrm{N}$, Nakajima $\mathrm{T}$, Urata A. Analytical investigation on cell temperature control method of planar solid oxide fuel cell. Energy Convers Manag. 2006; 47: 2319-2328.

17. Fardadi M, Mueller F, Jabbari F. Feedback control of solid oxide fuel cell spatial temperature variation. J Power Sources. 2010; 195: 4222-4233.

18. Hosseini S, Vijay P, Ahmed K, Tadé MO, Pareek V, Utikar R. Dynamic tank in series modeling of direct internal reforming SOFC. Int J Energy Res. 2017; 41: 1563-1578.

19. Vijay $P$, Hosseini $S$, Tadé MO. A novel concept for improved thermal management of the planar SOFC. Chem Eng Res Des. 2013; 91: 560-572.

20. Tang S, Amiri A, Vijay $P$, Tadé MO. Development and validation of a computationally efficient pseudo 3D model for planar SOFC integrated with a heating furnace. Chem Eng J. 2016; 290 : 252-262. 
21. Amiri A, Tang S, Vijay P, Tadé MO. Planar solid oxide fuel cell modeling and optimization targeting the stack's temperature gradient minimization. Ind Eng Chem Res. 2016; 55: 74467455.

22. Ahmed K, Föger K. Analysis of equilibrium and kinetic models of internal reforming on solid oxide fuel cell anodes: Effect on voltage, current and temperature distribution. J Power Sources. 2017; 343: 83-93.

23. Xu J, Froment GF. Methane steam reforming, methanation and water-gas shift: I. Intrinsic kinetics. AlChE J. 1989; 35: 88-96.

24. Achenbach E, Riensche E. Methane/steam reforming kinetics for solid oxide fuel cells. J Power Sources. 1994; 52: 283-288.

25. Tingey GL. Kinetics of the water-Gas equilibrium reaction. I. The reaction of carbon dioxide with hydrogen. J Phys Chem. 1966; 70: 1406-1412.

26. Anderson T, Vijay P, Tade MO. An adaptable steady state Aspen Hysys model for the methane fuelled solid oxide fuel cell. Chem Eng Res Des. 2014; 92: 295-307.

27. Ahmed K, Amiri AO. Tadé M. Simulation of solid oxide fuel cell anode in aspen HYSYS-A study on the effect of reforming activity on distributed performance profiles, carbon formation, and anode oxidation risk. Processes. 2020; 8: 268.

28. Amiri A, Vijay P, Tadé MO, Ahmed K, Ingram GD, Pareek V, et al. Solid oxide fuel cell reactor analysis and optimisation through a novel multi-scale modeling strategy. Comput Chem Eng. 2015; 78: 10-23.

29. Amiri A, Vijay P, Tadé MO, Ahmed K, Ingram GD, Pareek V, et al. Planar SOFC system modeling and simulation including a 3D stack module. Int J Hydrog Energy. 2016; 41: 2919-2930.

30. Tang, S, Amiri A, Tadé MO. System level exergy assessment of strategies deployed for solid oxide fuel cell stack temperature regulation and thermal gradient reduction. Ind Eng Chem Res. 2019; 58: 2258-226

31. Amiri A., Tang S, Steinberger-Wilckens R, Tadé MO. Evaluation of fuel diversity in solid oxide fuel cell system. Int J Hydrog Energy. 2018; 43: 23475-87.

32. Powell M, Meinhardt K, Sprenkle V, Chick L, Mcvay G. Demonstration of a highly efficient solid oxide fuel cell power system using adiabatic steam reforming and anode gas recirculation. J Power Sources. 2012; 205: 377-384.

33. Amiri A, Ahmed K, Tadé MO. A steady-state and dynamic simulation tool for solid oxide fuel cell operation applications. Comput Aided Chem Eng. 2019; 46: 595-600.

34. Sharma AK, Ahmed K, Birgersson E. Nernst voltage losses in planar fuel cells caused by changes in chemical composition: Effects of operating parameters. Ionics 2018; 24: 2047-2054.

35. Huang B, Qi Y, Murshed M. Solid oxide fuel cell: Perspective of dynamic modeling and control. J Proc Control. 2011; 21: 1426-1437.

36. Vijay $P$, Tadé MO, Shao Z. Adaptive observer based approach for the fault diagnosis in solid oxide fuel cells. J. Process Control. 2019; 84: 101-114.

37. Noren DA, Hoffman MA. Clarifying the Butler-Volmer equation and related approximations for calculating activation losses in solid oxide fuel cell models. J Power Sources. 2005; 152: 175-181.

38. Mann RF, Amphlett JC, Peppley BA, Thurgood CP. Application of Butler-Volmer equations in the modeling of activation polarization for PEM fuel cells. J Power Sources. 2006; 161: 775-781.

39. Vijay P, Tadé MO. Improved approximation for the Butler-Volmer equation in fuel cell modeling. Comput Chem Eng. 2017; 102: 2-10. 
40. Bessler WG. A new computational approach for SOFC impedance from detailed electrochemical reaction-diffusion models. Solid State Ion. 2005; 176: 997-1011.

41. Vijay $P$, Samantaray AK, Mukherjee A. Development of a thermodynamically consistent kinetic model for reactions in the solid oxide fuel cell. Comput Chem Eng. 2010; 34: 866-877.

42. Ederer M, Gilles ED. Thermodynamically feasible kinetic models of reaction networks. Biophys J. 2007; 92: 1846-1857.

43. Vijay $P$, Tadé MO, Datta R. Insights into the applicability of the $\mathrm{R}$ dot approach for reaction mechanism kinetics studies. Chem Eng Sci. 2012; 69: 616-627.

44. Vijay P, Tadé MO, Fishtik I, Datta R. A graph theoretical approach to the elucidation of reaction mechanisms: Analysis of the chlorine electrode reaction. Comput Chem Eng. 2013; 49: 85-94.

45. Dar YR, Vijay $P$, Tadé MO, Datta R. Topological analysis of hydrogen oxidation reaction kinetics at $\mathrm{Ni} / \mathrm{YSZ}$ anode of the solid oxide fuel cell. J Electroanal Chem. 2012; 677-680: 15-23.

46. Connor PA, Yue X, Savaniu CD, Price R, Triantafyllou G, Cassidy M, et al. Tailoring SOFC electrode microstructures for improved performance. Adv Energy Mater. 2018; 8: 1800120.

47. Zhang Y, Sun Q, Xia C, Ni M. Geometric properties of nanostructured solid oxide fuel cell electrodes. J Electrochem Soc. 2013; 160: F278.

48. Ruiz-Morales JC, Canales-Vázquez J, Peña-Martínez J, Marrero-López D, Irvine JT, Núñez P. Microstructural optimisation of materials for SOFC applications using PMMA microspheres. J Mater Chem. 2006; 16: 540-542.

49. Hanifi AR, Laguna-Bercero MA, Sandhu NK, Etsell TH, Sarkar P. Tailoring the microstructure of a solid oxide fuel cell anode support by calcination and milling of YSZ. Sci Rep. 2016; 6: 27359.

50. Jiang SP. Nanoscale and nano-structured electrodes of solid oxide fuel cells by infiltration: Advances and challenges. Int J Hydrog Energy. 2012; 37: 449-470.

51. Vijay $P$, Tadé MO, Shao Z, Ni M. Modeling the triple phase boundary length in infiltrated SOFC electrodes. Int J Hydrog Energy. 2017; 42: 28836-28851.

52. Vijay $P$, Tadé MO, Shao Z. Model based evaluation of the electrochemical reaction sites in solid oxide fuel cell electrodes. Int J Hydrog Energy. 2019; 44: 8439-8459.

53. Chen D, Zhang Q, Lu L, Periasamy V, Tade MO, Shao Z. Multi scale and physics models for intermediate and low temperatures $\mathrm{H}^{+}$-solid oxide fuel cells with $\mathrm{H}^{+} / \mathrm{e}^{-} / \mathrm{O}^{2-}$ mixed conducting properties: Part A, generalized percolation theory for LSCF-SDC-BZCY 3-component cathodes. J Power Sources. 2016; 303: 305-316.

54. Vijay P, Tadé MO, Shao Z. Statistical method-based calibration and validation of a solid oxide fuel cell model. Int J Energy Res. 2019; 43: 2478-2500.

55. Vijay $P$, Tadé MO, Datta R. Effect of the operating strategy of a solid oxide fuel cell on the effectiveness of decentralized linear controllers. Ind Eng Chem Res. 2011; 50: 1439-1452.

56. Vijay $P$, Tadé MO. An adaptive non-linear observer for the estimation of temperature distribution in the planar solid oxide fuel cell. J Process Control. 2013; 23: 429-443.

57. Vijay P, Tadé MO, Ahmed K, Utikar R, Pareek V. Simultaneous estimation of states and inputs in a planar solid oxide fuel cell using nonlinear adaptive observer design. J Power Sources. 2014; 248: 1218-1233.

58. Ahmed K, Föger K. Fuel processing for high -temperature high-efficiency fuel cells. Ind Eng Chem Res. 2010; 49: 7239-7256. 
59. Ceramic fuel cells limited technology update: Substantial reduction of stack degradation rates achieved. Melbourne: Ceramic Fuel Cells Ltd; 2014. Available from: http://www.asx.com.au/asxpdf/20140630/pdf/42qi2zq90rbhxt.pdf.

60. Ahmed K, Föger K. Perspectives in solid oxide fuel cell based micro-combined heat and power systems. J Electrochem Energy Convers Storage. 2017; 14: 031005.

61. Föger K. Materials Basics for Fuel Cells. New York: Woodhead; 2009.p.6-p.64.

62. Udomsilp D, Rechberger J, Neubauer R, Bischof C, Thaler F, Schafbauer W, et al. MetalSupported solid oxide fuel cells with exceptionally high power density for range extender systems. Cell Rep Phys Sci. 2020; 1: 100072.

63. Leah R, Bone A, Lankin M, Selcuk A, Pierce R, Rees L, et al. Low cost, REDOX-stable, lowtemperature SOFC developed by ceres power for multiple applications: Latest development update. ECS Trans.2013; 57: 461.

64. James BD, DeSantis DA. Manufacturing costs and installed price analysis of stationary fuel cell systems.Arlington,VA: Strategic Analysis Inc; 2015.

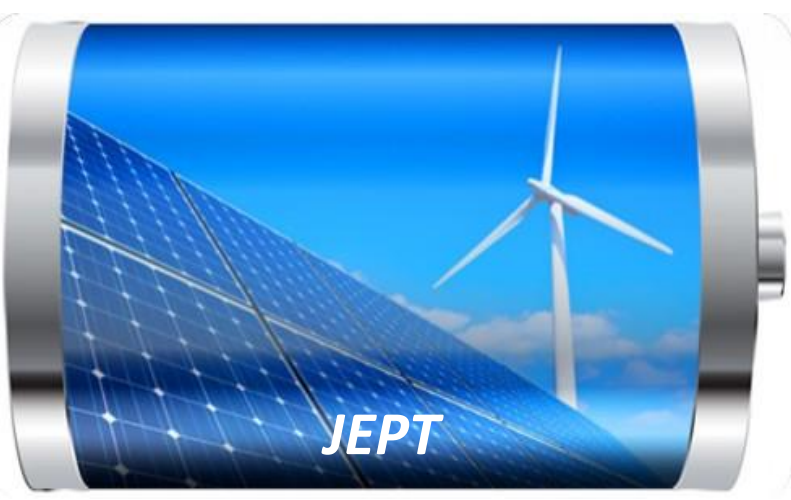

Enjoy JEPTby:

1. Submitting a manuscript

2. Joining in volunteer reviewer bank

3. Joining Editorial Board

4. Guest editing a special issue

For more details, please visit:

http://www.lidsen.com/journal/jept 